\title{
Interlink between Nuclear Receptors, Posttranslational Modifications and the Biological Clock in Health and Diseases
}

\author{
Mohamed Boudjelal $^{1 *}$, Danuta E. Mosskowsaka² and Stuart Farrow ${ }^{3}$ \\ ${ }^{1}$ King Abdullah International Medical Research Center, National Guard Health Affairs, PO Box 22490 (MBC 1515), Riyadh 11426, Saudi Arabia \\ ${ }^{2}$ Department of Biological Reagents and Assay Development, Molecular Discovery Research, GlaxoSmithKline, Gunnels Wood Road, Stevenage SG1 2NY, UK \\ ${ }^{3}$ Respiratory Therapy Area, GlaxoSmithKline, Gunnels Wood Road, Stevenage SG1 2NY, UK
}

\begin{abstract}
The day and night cycle influences the body function in health and disease through the modulation of the biological clock in via the Suprachiasmatic Nucleus (SCN) which in turn acts as the master clock in aligning the downstream clocks in the peripheral organs. The peripheral clocks can also be entrained independently by different factors such as external nutritional, hormonal and chemical cues that in many cases come from ligand modulation of nuclear receptors and kinase activators. Disruption of the molecular clock is associated with many diseases including cancer, immune diseases and aging. In addition, administration of toxic drugs such as anti-cancer can disturb the clock. These examples lead to changes in the sleep pattern of the patient and consequently can accelerate the manifestation of disease. This review details the function of the molecular clock in health and disease and how nuclear receptors and posttranslational modifications interact with the clock to regulate its function. In addition this review describes how chronotherapy can be applied in the clinical setting to treat cancer patients.
\end{abstract}

\begin{abstract}
Abbreviations: SCN: Suprachiasmatic Nucleus; CCGs: Clockcontrolled Genes: NR: Nuclear Receptor; CLOCK: Circadian Locomotors Output Cycles Kaput (Clock); BMAL1: Brain and Muscle Aryl Hydrocarbon Receptor Nuclear Translocator like - Arntl (BMAL); NPAR2: Neuronal PAS Domain Protein 2 (NPAS2); Per1,2 and 3: Period Homolog 1, 2 and 3 Genes; Cry1 and 2: Cryptochrome Genes; REV-ERBs: v-erbA Related Protein EAR-1-Related (EAR-1R); RORs: Retinoid Orphan Receptors; EARs: V-erbA Related Proteins; RARs: Retinoic Acid Receptors; RXRs: Retinoid X Receptors; PPARs: Preroxisome Proliferator Activated Receptors; PGC-1 $\alpha$ : PPAR $\gamma$ coactivator- $1 \alpha$; ERs: Estrogen Receptors; GR $\alpha$ and $\beta$ : Glucocorticoid Receptor Alpha and Beta; HNF4 $\alpha$ : Hepatocyte Nuclear Factor $4 \alpha$; NFкB: Nuclear Factor-Kappa B; AP1: Activator Protein 1; CCN1/CYR61: Cysteine-Rich, Angiogenic Inducer, 61; IFNs: Interferons; CK: Casein kinase; PKC: Protein Kinase C; PKA: Protein Kinase A; MKK7: MAP (Mitogen-Activated Protein) Kinase Kinase; MAP: Mitogen-activated Protein; ERK: Extracellular Signal-Regulated Kinase; JNK: c-Jun N-terminal Kinase; GSK-3 $\beta$ : Glycogen Synthase Kinase 3 Beta; cAMPK: 3'-5'-cyclic Adenosine Monophosphate-activated Protein Kinase; CDK: Cyclin-dependent Kinase; TGF- $\beta$ : Transforming Growth Factor $\beta$; 5-FU: 5-flurouracil; PEPCK: Phosphoenolpyruvate Carboxylase; SIRT1: Silent Mating Type Information Regulation 2 Homolog 1; HDAC: Histone Deacetyltransferase; HAT: Histone Hcetyltransferase; $\mathrm{NAD}^{+}$: Nicotinamide Adenine Dinucleotide; PARP1: Poly(ADPribose) Polymerase 1; MDD: Major Depressive Disorder; BD: Bipolar Disorder
\end{abstract}

\section{Introduction}

The regulation of the body rhythm is governed by the biological clock and is commonly referred to as the circadian rhythm. Its role is to maintain the adaptation of the body to the environmental changes during the day and night through regulating the pathways governing many physiological processes. The biological clock exists in most if not in all organisms; from bacteria, plants to humans. It is an essential component of the cells and organs. In the mammalian system, there are two clocks; the central clock is located in the suprachiasmatic nucleus (SCN) and can synchronize the secondary clocks found in the peripheral organs and tissues through hormonal secretion such as melatonin and cortisol level as well as modulating the body temperature [1].
The molecular clock is able to regulate a complex network of genes and pathways that leads to their oscillation with a period of circa 24 hours. Comprehensive studies were carried out to dissect the circadian clock in cyanobacteria, neurospora, Arabidopsis, drosophila and mammals and to understand its role in health and diseases. Gene microarray studies determined that up to $10 \%$ of the transcript $[2,3]$ is governed by the circadian clock regulating metabolism, cell cycle, development, nutrient update and many more pathways. Disruption of the clock function can damage the organism [4].

At the anatomical level, complex neuronal networks in the anterior hypothalamus compose the SCN central pacemaker involved in producing synchronized outputs to regulate the clock in the brain and in the peripheral clocks in the different tissues throughout the body. These later clocks are self-sustained: circadian oscillations intrinsic to each cell can occur autonomously, without any environmental signals. To sustain the oscillation of the peripheral clocks at the approximate periodicity of $24 \mathrm{~h}$, synchronization is influenced by the external cues that are known as zeitgebers. The synchronization process, called entrainment, is an important aspect to reset the clock on the daily basis and prevent it from running out of phase. Light is the most prevalent external cue that can synchronize the central clock; it is detected by the photoreceptor cells in the retina and the signal gets transmitted via the retinohypothalamic tract (RHT) in the SCN [5]. This in turn sets the cascade of signaling pathways to stimulate the neurons that lead to the activation of a transcriptional program of clock-controlled

*Corresponding author: Mohamed Boudjelal, King Abdullah International Medical Research Center, National Guard Health Affairs, PO Box 22490 (MBC 1515), Riyadh 11426, Saudi Arabia, E-mail: boudjelalmo@ngha.med.sa

Received March 22, 2013; Accepted May 20, 2013; Published May 31, 2013

Citation: Boudjelal M, Mosskowsaka DE, Farrow S (2013) Interlink between Nuclear Receptors, Posttranslational Modifications and the Biological Clock in Health and Diseases. J Carcinogene Mutagene S14: 005. doi:10.4172/2157-2518. S14-005

Copyright: (c) 2013 Boudjelal M, et al. This is an open-access article distributed under the terms of the Creative Commons Attribution License, which permits unrestricted use, distribution, and reproduction in any medium, provided the original author and source are credited. 
Citation: Boudjelal M, Mosskowsaka DE, Farrow S (2013) Interlink between Nuclear Receptors, Posttranslational Modifications and the Biological Clock in Health and Diseases. J Carcinogene Mutagene S14: 005. doi:10.4172/2157-2518.S14-005

genes (CCGs). In non-brain tissues like the liver, heart, kidney and skin, the peripheral clocks are implicated in the regulation of local transcriptional activity. These clocks are also entrained by external cues mainly temperature and feeding schedules [6].

Across species, the molecular mechanism of the biological clock is evolutionarily conserved and its role is essential for maintaining an optimal activity and regulation of several processes at the cellular level. As summarized in Figure 1, it governs the sleep-wake cycles, memory consolidation, metabolism of nutrients, toxins and drugs, bone formation, hormone regulation, immunity, cell growth and cycle. Several pathways are known to be highly regulated by the clock such as heart rate, blood pressure and body temperature [7-9]. Moreover, many diseases and disorders are associated with malfunctions of the circadian clock such as cancer, familial sleep disorders (FASPS), bipolar disorder, sleep problems in the elderly, seasonal affective disorders (SAD), diabetes and obesity [10-13].
Taking into consideration that the molecular clock acts directly on the genome it is not surprising that the proteins of the clock work in either competition and/or cooperation with many transcription factors. In addition, the expression and activity of its components are in turn regulated by other transcription factors. To add to the complexity, the biological clock is influenced by one of the most dynamic liganded transcription factors in the cells, the nuclear receptors as detailed in the following section. Nuclear receptors are a small family of transcription factors that transmit the signals of many nutrients and hormones into cells and they have been the focus of many drug discovery programs that have yielded some of the most widely used medicines in the market as steroids and Vitamin A based drugs [14].

This review describes the latest understanding of the central and peripheral clock composition. As the biological clock governs the transcription of almost of $10 \%$ of the genome directly, we will address

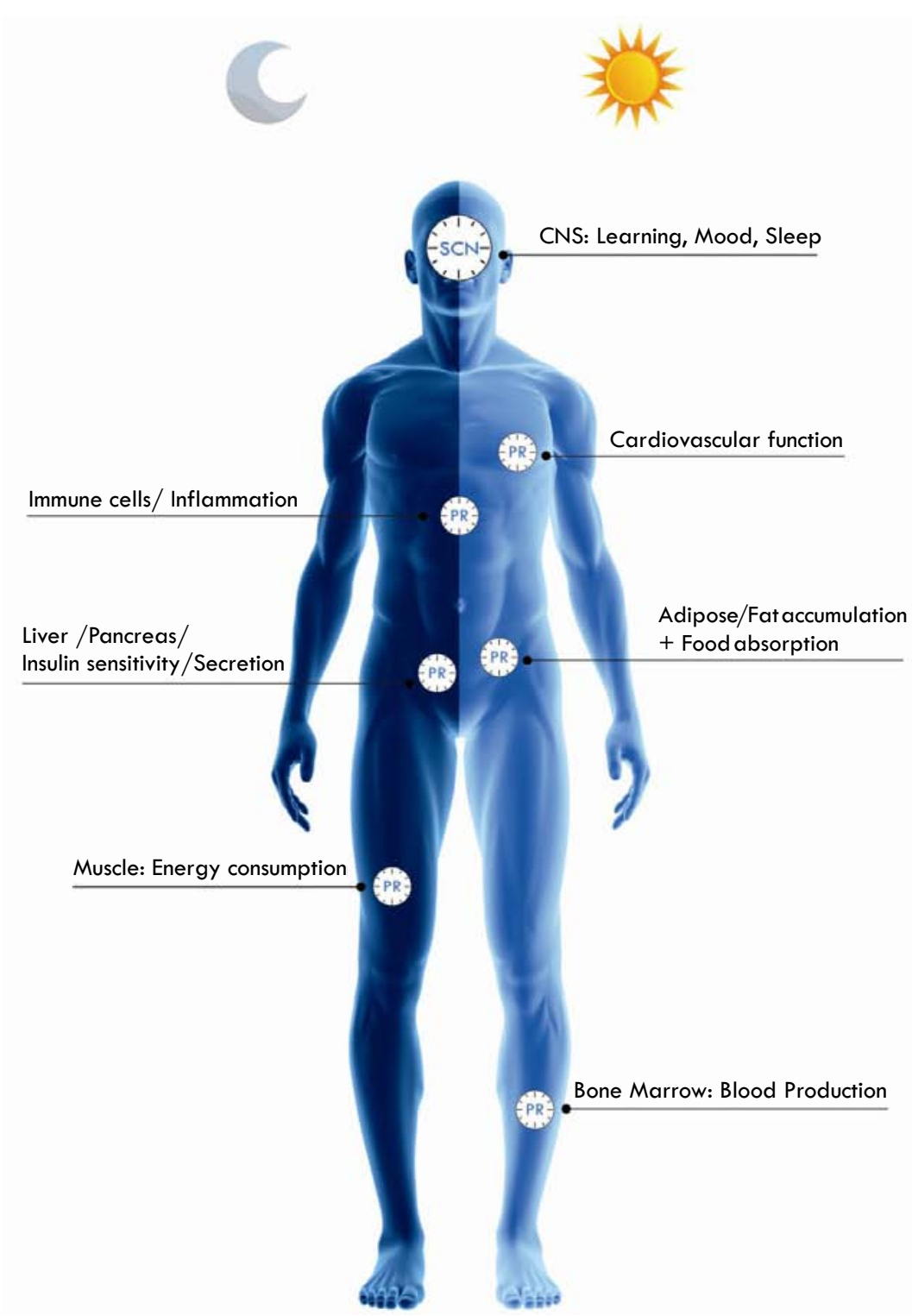

PR: Peripheral clock; SCN: Suprachiasmatic nucleus

Figure 1: Role of the biological clock in regulating the physiological process across the body. 
Citation: Boudjelal M, Mosskowsaka DE, Farrow S (2013) Interlink between Nuclear Receptors, Posttranslational Modifications and the Biological Clock in Health and Diseases. J Carcinogene Mutagene S14: 005. doi:10.4172/2157-2518.S14-005

in this review, the interlink between the molecular clock, a selected number of nuclear receptors involved in common diseases and also the posttranslational modifications that affect both. It gives the reader a grasp on the versatility of biological clock regulation mechanisms and demonstrates the multiple opportunities for medical intervention when addressing diseases linked to the clock.

\section{The Biology of the Molecular Clock}

De Mairan, the French astronomer, was the first to report of the clock in 1729. He observed that the movements of the leaves of Mimosa pudica continue to open and close every 24 hours even in constant darkness [15]. In the 70's the molecular mechanism underlying the clock was discovered in Drosophila followed by comprehensive studies in 90's that lead to the model of the clock mechanisms [16]. Our current understanding of the biological clock is clearer now that it has been linked to many physiological networks and the future focus is how to convert these molecular insights into patient benefit. It is now well defined that the composition of the clock is not conserved across kingdoms, but the consequences of its function is the same across species. At the molecular level, in mammals the clock is composed on two feedback loops: the Primary and Secondary loops are co-regulated by other transcription factors such as nuclear receptors $[17,18]$.

\section{Primary feedback loop}

In mammals, the cellular oscillator is similar in both SCN and peripheral tissues, containing interlocking negative feedback loops. As summarized in Figure 2, the primary feedback clock loop is formed from the gene products of the transcription factors, circadian locomotors output cycles kaput (Clock), brain and muscle aryl hydrocarbon receptor nuclear translocator like - Arntl (BMAL) and or Neuronal PAS domain protein 2 (NPAS2).

CLOCK, BMAL1, and NPAS2 form hetermomeric complexes, CLOCK/BMAL1 and NPAS2/BMAL1, which form the central node in the network and the transcription initiator of the feedback loops. NPAS2 is highly related in primary amino acid sequence to CLOCK. CLOCK/BMAL1 and NPAS2/BMAL1 drive expression of the Period 1 $/ 2$ and cryptochrome1/2 genes. They bind to E-box cis-elements in the promoter regions of target genes Period homolog 1, 2 and 3 genes (Per1, Per2, and Per3), Cryptochrome genes (Cry1, Cry2). The encoded Per1/2 and Cry1/2 proteins in turn heterodimerise and repress CLOCK/ BMAL1 and NPAS2/BMAL1 activity to inhibit their own expression. This latter negative Per/Cry feedback loop is commonly seen as the primary generator of the circadian rhythm. Transcription of Pers and Crys is initiated during the circadian day. Aided by posttranslational modifications, Per and Cry proteins enter the nucleus, probably as a multimeric complex (Per/Cry), and inhibit CLOCK/BMAL1-mediated transcription after a certain delay. The Per or Cry complex is degraded during the night, which releases its inhibitory action on CLOCK/ BMAL1 and allows a new cycle of transcription to take place [18].

\section{Secondary feedback loop}

The molecular clock adapts its function in certain cell types with a secondary feedback loop that involves other transcription factors and posttranslational modification loops. As the molecular clock governs at least $10 \%$ of the genome, it is more likely that these feedback loops are the evolutionary adaptors of the clock for every specialized cell and that each process has a distinct loop to differentiate its functions. The best characterized loop to date, is the secondary loop orchestrated by REV-ERB $\alpha$ and ROR $\alpha$ nuclear receptors [19].

The REV-ERBs (REV-ERB $\alpha$ and REV-ERB $\beta$ ) were first identified as orphan nuclear receptors based on homology searching of nuclear receptor (NR) domain structure. They are expressed in adipose tissue, skeletal muscle, the brain and liver. REV-ERB $\beta$ is very highly expressed in parts of the brain (pineal and prefrontal cortex), thyroid, uterus and pituitary, whereas REV-ERB $\alpha$ is expressed highly in immune cells such as macrophages. REV-ERBs are transcriptional repressors because

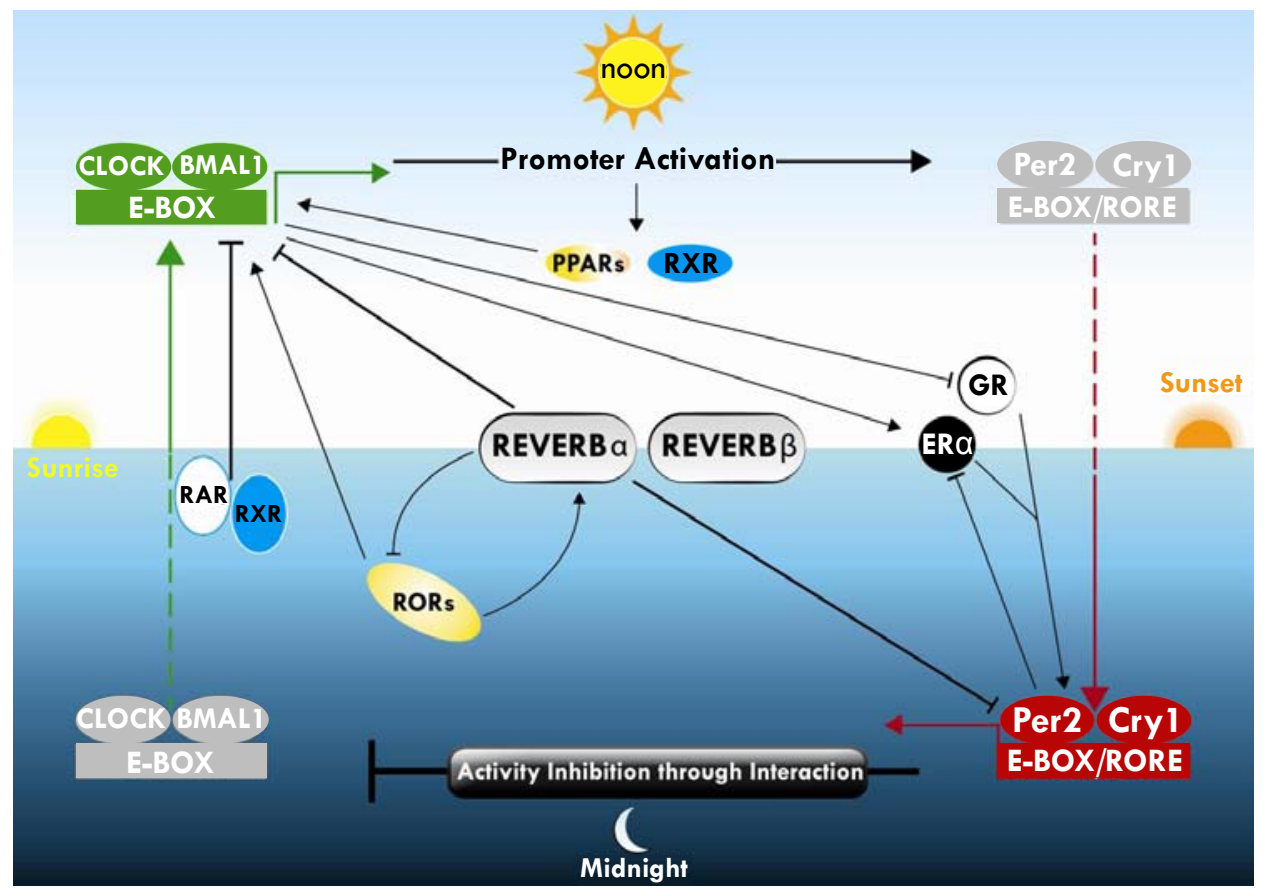

Figure 2: The Primary and Secondary Feedback loops of the molecular and implication of nuclear receptors in their regulation. 
they lack the activation-function 2 (AF-2) region, which is involved in coactivator binding that allow them to bind co-repressor proteins such as the nuclear receptor corepressor (NCoR) [20].

In contrast to REV-ERBs, ROR (Retinoid Orphan Receptor) subfamily of nuclear receptors is transcription factors. The first member of this subfamily to be discovered is RORa based on sequence similarities to the retinoic acid receptors (RARs) and the RXRs. The highly similar receptors, $\operatorname{ROR} \beta$ and $\operatorname{ROR} \gamma$, were identified soon thereafter $[21,22]$.

Each ROR gene generates multiple isoforms based on alternative promoter usage with all of the isoforms varying only in the aminoterminal region of the receptor. Tissue expression of RORa includes the liver, skeletal muscle, skin, lungs, adipose tissue, kidney, thymus and brain. The expression of ROR $\beta$ is limited to the CNS. The two other isoforms of ROR $\gamma$ are found in both humans and mice ( $\gamma 1$ and $\gamma 2)$. ROR $\gamma 2$ is often regarded as ROR $\gamma t$ and is found primarily in the immune system. ROR $\gamma 1$ is most highly expressed in the liver, skeletal muscle, adipose tissue and kidney [23].

Both the RORs and REV-ERBs bind to the same DNA response elements termed Retinoid Orphan Receptor Binding Element (RORE). They can both bind as a monomer to the RORE, an AGGTCA 'half site' with a 5'AT-rich extension. They can also form homodimers and while REV-ERBs function as transcriptional silencers, RORs function as activators [24].

As mentioned and described in Figure 2, the RORa and REV$\mathrm{ERB} a$ form the core components of the secondary feedback loop of the circadian clock and in this regard, they are the major regulators of the cyclic expression of BMAL1 and CLOCK. More interestingly, REVERB $a$ transcription is activated by the BMAL1/CLOCK heterodimer and transrepressed by Cry/Per, resulting in circadian oscillations of REV-ERBa. In turn, REV-ERB $\alpha$ represses BMAL1 and CLOCK transcription. REV-ERB $\beta$ expression also oscillates in a circadian fashion and can repress BMAL1 transcription. RORa competes with REV-ERB $\alpha$ for binding of their shared DNA binding elements, the RORE, in the BMAL1 promoter leading to BMAL1 expression being repressed by REV-ERB $\alpha$ and activated by ROR $\alpha$. The oscillating expression of ROR $\alpha$ and REV-ERB $\alpha$ in the SCN leads to the circadian pattern of BMAL1 expression. This REV-ERBa/RORa feedback loop interconnects the positive and negative limbs of the core circadian clock.

NPAS2, like CLOCK, forms heterodimers with BMAL1 and effectively functions in the regulation of mammalian circadian rhythms. NPAS2, like BMAL1, is a RORa and REV-ERBa target gene. NPAS2 promoter has an RORE and it has been demonstrated that both ROR $\alpha$ and REV-ERBa regulate the expression of NPAS2, thus suggesting a mechanism by which ROR $a$ and REV-ERBa coordinately regulate the positive limb of the circadian clock [25-28].

\section{Interlink between Nuclear Receptors and Clock Feedback Loops}

Nuclear receptors (NRs) play an important role in modulating the circadian clock and the circadian control of various metabolic processes. NRs are composed of 49 family members and are transcription factors with a highly precise mechanism of repressing, activating or indirectly modulating the expression of various genes in the genome [29]. Binding of ligand to NRs elicits a series of sequential conformational changes, which lead to release of the co-repressor complex and recruitment of co-activators. Consequently, the activated NR induces target gene expression.

Based on their structures, the NR family is classified into three groups: steroid hormone receptors that generally bind DNA as homodimers and are activated with high-affinity by steroid hormones. Members of this group include the receptor for glucocorticoids, mineralocorticoid, estrogen, androgen and progesterone [14] Members of second group function as heterodimers with retinoid $\mathrm{x}$ receptors (RXRs) and include the receptors for retinoic acid (RARs), fatty acids (PPARs), bile acids (farnesoid $x$ receptor, FXR), oxysterols (liver $\mathrm{x}$ receptor, LXR), xenobiotics (pregnane $\mathrm{x}$ receptor, PXR) and constitutive androstane receptor (CAR). Members of the third group are orphan NRs for which no endogenous ligands have yet been identified, or which appear to lack a functional ligand-binding domain based on structural analysis. Members of this group include REV-ERBs, RORs, nerve growth factor-induced clone B, NR related 1 , neuron-derived orphan receptor 1 , small heterodimer partner, liverrelated homologue 1 and hepatocyte nuclear factor $4 \alpha$ (HNF4 $\alpha$ ) [30].

Beside REV-ERBs and RORs other NRs are involved in the clock photic resetting mechanism. Mice lacking EAR2, an orphan NR, display an unstable circadian locomotor activity rhythm and abnormal light resetting [31]. These mice lose Per1 circadian expression and have a dampening of Per2 circadian expression in the frontal cortex as well as an altered resynchronization after a light-dark cycle phase shift. Mice lacking the thyroid hormone receptor- $\beta$ (NR1A2) are devoid of mid-wavelength cones and consequently have an abnormal light entrainment and phase-shifting response [32].

In addition, the estrogen receptor- $\beta(\mathrm{ER} \beta)$ and retinoid $\mathrm{X}$ receptors (RXRs) are expressed in retinal ganglion cells. It would be important to analyze more systematically the light-induced phase-shifting response of null mutants of these receptors or ligand treated animals. In addition to the NR role in the photonic synchronization, they are also involved in non-photonic entrainment of the clock, especially the peripheral clock. Below is a summary of the mechanism by which the major nuclear receptors affect the clock with focus on retinoid, steroid and fatty acid nuclear receptors. They represent the main transmitters of nutrient external cues that influence the clock entrainment in health and diseases.

\section{Retinoic acid and retinoid $\mathrm{X}$ receptors and the clock}

Retinoic acid and retinoid $\mathrm{x}$ receptors are receptors for vitamin $\mathrm{A}$ and its derivatives that work to transmit metabolic signals to modulate gene expression that in turn can influence the biological clock. The Vitamin A effect on the clock has been shown to differ depending on the tissues studied. In this regard, it has been shown that vitamin A deficiency modifies CLOCK/BMAL1 and PER1 daily rhythmicity in the animal's hippocampus when animals are maintained fewer than $12 \mathrm{~h}$ light: $12 \mathrm{~h}$ dark condition. In the hippocampus, the expression of retinoic acid nuclear receptors, (RARs) and retinoid $\mathrm{X}$ receptors (RXRs) have been detected. The deficiency of nutritional vitamin A, phase shifted BMAL1 and abolished Per1 circadian expression at both mRNA and protein levels. In addition, the analysis of the RAR and RXR promoters identified E-boxes for BMAL1 binding as well as retinoidrelated orphan receptor responsive element sites, which display an endogenously controlled circadian expression in the rat hippocampus. The temporal expression of RARs and RXRs profiles were modified when animals were fed with a vitamin-A-deficient diet [33]. However, another study showed that the expression of clock genes, BMAL1 and Per2 were not affected in vitamin A deficient mice which may suggest 
that the effect of vitamin A on the clock through its nuclear receptors RARs and RXRs could be a tissue specific [34].

It has been shown also that RARa and RXRa interact directly with CLOCK, an interaction that negatively regulates CLOCK/BMAL1mediated transcriptional activation of clock gene expression in vascular cells. In addition, retinoic acid can phase shift Per2 mRNA rhythmicity in mice [35]. In summary, these are evidences that demonstrate the involvement of RARs and RXRs in biological clock regulation. However, more studies are needed to dissect the role of RARs and RXRs in clock regulation in more details.

\section{Glucorticoid receptors and the clock}

The most powerful chemical synchronizer of the clock is the glucocorticoid hormone that is secreted rhythmically with maximum plasma levels at the end of the sleep phase in mammals [36]. Interestingly the resetting of the clock by light occurs only during the dark period in mammals but glucocorticoids could phase shift peripheral clocks at any time of the light-dark cycle [37].

Glucocorticoids are the natural ligand of the glucocorticoid receptors, GRs. These receptors exist in two isoforms, GR $\alpha$ and GR $\beta$ that are generated through alternative splicing of exon 9 of the gene. In the cells, there are GR $\alpha$ and $\beta$ variants termed A through $D$ generated from at least 8 initiation sites and produce GR $\alpha$ and $\beta$ proteins that have different specificity and affinity to glucocoticoid-responsive genes as well as differentially expressed in tissues and cells [38]. In contrast to GR $\alpha, G R \beta$ does not bind ligand and it is widely expressed. GR $\alpha$ modulates signal transduction cascades through protein-protein interactions with others transcription factors such as NF- $k B$ and AP1. GR $\alpha$ influences the ability of NF- $\mathrm{kB}$ and AP1 to stimulate or inhibit the transcription rates of their respective target genes $[39,40]$.

The secretion of glucocorticoids is tightly regulated by the circadian, negative feedback and stress-related activities of the HPA axis that are integrated by higher brain centers [41]. In humans, cortisol levels have a diurnal rhythm curve that reach their highest peak in the early morning, with the purpose of helping adjust the body's activities to the regular periodicity of day/night changes. Underlying mechanisms for the alteration of local glucocorticoid actions, however, have not been well elucidated yet. However, it has been found that the circadian rhythm transcription factor CLOCK physically interacts and acetylates the GRa at a multiple lysine cluster located in its hinge region, and represses GRa-induced transcriptional activity of several glucocorticoid-responsive genes [41]. In addition to the diurnal secretion of circulating glucocorticoids controlled by the master CLOCK, peripheral CLOCK negatively regulates GR $\alpha$-induced transcriptional activity through acetylation of the GRa [42].

Moreover, it has been recently identified that glucocorticoids induce the expression of Per1 gene as an additional mechanism of regulating the clock [42].

\section{Estrogen receptors and the clock}

The effect of estrogens, such as $17-\beta$ estradiol $\left(E_{2}\right.$ is mediated by estrogen receptors (ER $\alpha$ and ER $\beta$ modify the pattern of expression of specific target genes. This happens either directly through interaction with cognate DNA sequences (estrogen-responsive elements, EREs) or through protein/protein interaction with other transcription factors [43]. Binding of ligand to ERa induces the ordered recruitment of a series of coactivator complexes, leading to histone acetylation, methylation, chromatin remodeling and recruitment of the basal transcription machinery [44].
Deregulation of the core clock factor, Per2, has been reported in several human malignancies including breast cancer that is estradiol dependent [45]. It has been suggested Per2 plays a role in normal mammary cell differentiation [46]. Alternatively, Per2 has been demonstrated to block the estrogen inducing steroid sensitive genes mediated by ERa in breast cancer cell lines that include pS2, cyclin D1 and CCN1/CYR61. Inhibition of Per2 expression using the siRNA enhanced the estradiol inducing the expression of these genes. Moreover, the overexpression of Per2 inhibited the estradiol activated ERE-driven reporter assay [47]. In another study, it has been shown that the expression of the estrogen receptor $a$ gene oscillates in a circadian fashion in cultured human mammary epithelial cells. Whereas ER $\alpha$ positive breast cancer cells do not display circadian oscillation of ERa expression. The same study showed that the clock oscillation is maintained in normal epithelial breast cells but not in the cancerous cells, in both in ERa negative and positive cells [48]. The connection between estrogen receptor and the clock involves its interaction with the CLOCK protein in ligand dependent manner. In addition, the sumoylation of CLOCK can be stimulated with estrogen treatment. Sumoylation of CLOCK leads to increase the transcriptional activity of CLOCK and activity of ERa as shown by increased transcription of cyclin D1. Moreover, the sumoylation of CLOCK stimulated growth of breast cancer cell lines and increased the proportion of $S$ phase cells in the cell cycle [49]. In another study, it has been shown that the clock has a role in the production of steroid hormone including the estrogen and progesterone [50].

The results of these studies uncovered new insights into the connection between a major circadian protein and a major estrogendependent transcription factor, providing the basis for further research into the involvement of circadian proteins in breast cancer.

\section{The peroxisome proliferator-activated receptors and the clock}

In addition to glucocorticoid that can synchronize the peripheral clock, nutrition can also play the same role. The peripheral clocks can be synchronized independently from SCN in nocturnal rodents by feeding restriction [51]. Moreover, the expression of key genes involved in important metabolic pathways display circadian rhythm expression in liver and adipose tissue. Many nuclear receptors plays an important role in the regulation of these pathways and energy metabolism especially peroxisome proliferator-activated receptors (PPARs) which also play an important role in entraining the clock.

The PPAR subfamily is composed of three members PPARa, $\operatorname{PPAR} \beta / \delta$, and $\operatorname{PPAR} \gamma$ that function in regulating the transcriptional activities through heterodimirization with retinoid $\mathrm{X}$ receptor (RXR) and bind to specific DNA sequence elements termed PPREs. They are activated by wide variety of natural ligands such as unsaturated FAs, saturated FAs, eicosanoids and a few endocannabinoids and phospholipids. In addition, many PPAR synthetic ligands were developed to treat dyslipidemia and diabetes such as fibrate and thiazolidine-2, 4-diones or TZDs [52]. The PPARs are expressed broadly in the body, in the brown adipose tissue, liver, heart, kidney, and intestine, skin, gut, placenta, skeletal and heart muscles, adipose tissue, brain and immune and inflammatory cells [53]. Modulation of PPARs have emerged as an important mechanism to develop drugs to treat metabolic syndrome that is associated with obesity that is characterized by inflammation caused by macrophage infiltration and activation in adipose tissue and liver [54]. PPARs affect inflammation through direct and indirect mechanisms. For instance, PPARs 
upregulate the expression of I $\mathrm{B}$, which blocks the nuclear translocation and activation of the proinflammatory transcription factor NF- $\kappa \mathrm{B}$. In addition, it induces the expression of soluble interleukin-1 receptor antagonist (IL-1Ra) to promote anti-inflammatory effects; it also induces the expression of TGF- $\beta$ or through other protein-protein interactions [55-57].

As PPARs are in the centre of regulating the nutrient and energy/ metabolism, they represent one of the channels through which the metabolic cues entertain the biological clock. This model serves as a link between the clock genes and metabolism, and method through which various metabolic parameters can affect clock genes. Due to PPARs' robust relationship with energy status and metabolism, any alteration of PPARs can lead to abnormal function of the biological clock system and expression of genes in metabolic pathways. Extensive studies have been carried out to dissect the molecular mechanism linking the PPARs and components of the biological clock. First PPARa expression in rhythmic and is regulated by the CLOCK protein and diurnal expression is abolished in the liver of CLOCK-mutant mice $[58,59]$.

It has been found that BMALl1 promoter has PPRE that can bind PPAR $a$ in association with Per2 that plays a role of cofactor. Moreover, PPARa seems to play the same role as REV-ERBa in regulating expression of BMAL1. Moreover, CLOCK/BMAL1 heterodimers have been shown to increase the transcriptional activity of genes whose promoter contains PPAR response elements (PPREs). However, it seems that PPARs do not affect the expression of clock component proteins, BMAL1 and Per3, in the central clock but only in the peripheral clock as was shown in PPAR $\alpha$-null mice [60].

A recent paper provides a novel link between $\operatorname{PPAR} \beta / \delta$ and REV-ERBa, in which the mir-122, a microRNA abundantly found in hepatocytes that is upregulated by REV-ERBa can down-regulate $\operatorname{PPAR} \beta / \delta$ [61]. Knocking down of PPAR $\gamma$ abolishes rhythmicity of BMAL1, Cry1, Cry2, and Per2 in mice aorta. The PPAR $\gamma$-agonist rosiglitazone induces BMAL1 expression $[61,62]$.

PPAR $\gamma$ coactivator- $1 \alpha$ (PGC- $1 \alpha$ ), as the name implies, is a known coactivator of PPARs [63] and is well characterized as playing a part in the biological clock. PCG- $1 \alpha$ positively regulates the expression of clock components, including CLOCK, BMAL1, and REV-ERB $\alpha$. On the BMAL1 promoter, PGC- $1 \alpha$ binding is accompanied by an increase in histone $\mathrm{H} 3$ acetylation and histone 3 lysine 4 trimethylation (H3K4me3), two markers of transcriptional activation, while histone 3 lysine 9 dimethylation (H3K9me2), a marker that signifies transcription silencing, decreased. Thus, PGC- $1 \alpha$ serves as a potential factor which couples circadian rhythm to energy status [64].

In summary circadian clock proteins control PPAR expression by the following mechanisms: (a) activation of PPAR $\alpha$ transcription by CLOCK/BMAL1 heterodimer upon binding to the E-box in the PPAR $\alpha$ promoter and (b) downregulation of PPAR $\beta / \delta$ by microRNA stimulated by REV-ERBa (c) REV-ERBa is positively regulated by PPAR $\alpha$; (d) BMAL1 is positively regulated by both PPAR $\alpha$ and PPAR $\gamma$. (e) Indirectly by competing for common cofactors like PGC-1a that positively regulate the expression of clock genes [65].

\section{Posttranslational Modifications that have Dual Affect on the Nuclear Receptors and the Clock Components}

Posttranslational modification of biological clock proteins and their associates plays an important role in the modulation of clock function. These modifications are mainly phosphorylation, acetylation and methylation. The following section summarizes the most characterized posttranslational modifications focusing on those modifications that affect both the nuclear receptor and the clock as summarized in Table 1. The list will grow in the next few years as many researchers on clock start focusing on this aspect especially those studying the role of epigenetics in health and diseases.

Phosporylation modification has been shown to play an important role in the clock function and its entrainment [66]. For example CK1 phosphorylates Per1, Per2, BMAL1 and Cry. The phosphorylation of Per1 and 2 by CK1-3 targets them for proteosomal degradation. Moreover, the link between the CKIq activity and the clock is clinically demonstrated in the familial advanced sleep phase syndrome (FASPS) patients. In one group of these patients CKIq is mutated in which a threonine is replaced by alanine and has a reduced activity; in a second group the patients have mutated Per2 that has a reduced affinity to CK1. In both cases the affected individuals exhibit a phase shift in sleep-wake cycles and body temperature rhythms that are advanced by about 4 hours compared to average population $[67,68]$.

Casein kinase 2 also phosphorylates the Per2 and BMAL1 and leads to their either stabilization or destabilization depending on cell type. On the other hand, the inhibition or downregulation of CK2 activity lead to lengthened circadian period [69]. Another kinase that has been shown to phosphorylate the BMAL1, reduce its ubiquitylation, and increase its stability is $\mathrm{PKC} \gamma[70]$.

As described in Table 1, CK2 is able to phosphorylate PPAR $\gamma 1$ at S16/S21 and estrogen receptor alpha at serine 282 and 559. The phosphorylation of PPAR $\gamma$ lead to increase its transcriptional activity while it decreases the activity of ERa.The effect of PKC and PKA on nuclear receptors is diverse, while the PKA phosphorylate PPAR $\alpha$, ER $\alpha$ and RAR $\alpha$ and RAR $\gamma$ and decrease their transcriptional activity, the phosphoralation of ERa at S46/47 increase the estradiol receptor activation. PKC also phosphorylate the PPARa at T129, S179 and S230 and RAR $\alpha$ at S77/S157 and RORa, but these phosphorylation lead to decrease of their transcriptional activities.

The stress kinase MKK7 is a regulator of the circadian clock in mammalian cells. Genetic inactivation of MKK7 resulted in an extended period of oscillation in circadian gene expression in cells. Moreover exogenous expression of an MKK7-JNK fusion protein that functions as a constitutively active form of JNK induced phosphorylation of Per2. In addition JNK interacted with Per2 at both the exogenous and endogenous levels, and MKK7-mediated JNK activation increased the half-life of Per2 protein by inhibiting its ubiquitination. Notably, the Per2 protein stabilization induced by MKK7-JNK fusion protein reduced the degradation of Per2 induced by casein kinase $1 \varepsilon$ [71].

As summarized in Table 1 nuclear receptors are mostly phosphorylated by MAPKs that affect their transcriptional activity. MAPK, p38, ERK, JNK phosphorylate PPAR $\alpha, E R \beta, E R \alpha$, PPAR $\gamma$, GR $\alpha$, RAR $\gamma$, ROR $\alpha$, RXR $\alpha$ and PPAR $\beta$ at different sites. In most cases, these phosphorylations increase the receptor ligand dependent activation except for the phosphorylation of GRa at S211, S226 by p38 and phosphorylation of PPAR $\gamma$ by MAPK at S112 and by ERK/ JNK at $\mathrm{S} 84$ as well as phosphorylation of RXR by JNK at different sites that lead to decrease of their transcriptional activities. It remains to be determined the precise mechanism by which these phosphorylations on nuclear receptors affect the biological clock.

The phosphorylation of Per2 by GSK-3 $\beta$ is important for its nuclear transclocation [72]. GSK-3 $\beta$ also phosphorylates Cry2 that lead to its proteosomal degradation [73]. The inhibition of GSK-3 $\beta$ by lithium 
Citation: Boudjelal M, Mosskowsaka DE, Farrow S (2013) Interlink between Nuclear Receptors, Posttranslational Modifications and the Biological Clock in Health and Diseases. J Carcinogene Mutagene S14: 005. doi:10.4172/2157-2518.S14-005

Page 7 of 16

\begin{tabular}{|c|c|c|c|c|}
\hline Kinase & $\begin{array}{l}\text { Targeted Nuclear } \\
\text { Receptor }\end{array}$ & Targeted Residue & Effect & Reference \\
\hline \multirow{4}{*}{ PKC } & PPARa & T129, S179,S230 & Activation & {$[80]$} \\
\hline & ER $\alpha$ & S46/47 & Activation & [81] \\
\hline & RAR $\alpha$ & S77, 157 & Inhibition & [82] \\
\hline & RORa & $?$ & Inhibition & [83] \\
\hline \multirow{4}{*}{ PKA } & PPARa & N-terminal & Activation & {$[84]$} \\
\hline & ER $\alpha$ & S305, S236 & Inhibition & {$[85,86]$} \\
\hline & RARa & S369 & Inhibition & {$[87]$} \\
\hline & RARY & S360 & Inhibition & [88] \\
\hline CK-II & PPARy1 & S16, S21 & Activation & [89] \\
\hline CK2 & ERa & S282, S559 & Inhibition & [81] \\
\hline \multirow{2}{*}{ GSK3B } & ERa & S102,S104, S106, S118 & Activation & {$[90]$} \\
\hline & REV-ERBa & S55, S59 & Activation & [91] \\
\hline \multirow{4}{*}{ p38 } & PPARa & S6, S21, S12 & Mix effect depends on cell type & [92] \\
\hline & $E R \beta$ & S106, S124 & Activation & [93] \\
\hline & GR & S211 or S226 & Inhibition & {$[94]$} \\
\hline & RARY & S66-S68 & Activation & [95] \\
\hline \multirow{2}{*}{ MAPK } & PPARY & S112 & Inhibition & [96] \\
\hline & ERa & S118, S167 & Activation & {$[97]$} \\
\hline RAS/MAPK & ERa & T311 & Activation & {$[87]$} \\
\hline CDKs, MAPK, CKII & GR & S113. S141, S203, S211, S226 & Activation & {$[98]$} \\
\hline \multirow{3}{*}{ ERK } & PPARa & $\mathrm{S} 12, \mathrm{~S} 21$ & Activation & [99] \\
\hline & PPARY1 & S84 & Inhibition & [100] \\
\hline & RORa & T128 & Activation & [101] \\
\hline \multirow{2}{*}{ JNK } & $\mathrm{RXR} \alpha$ & S22, S61, S75, S87 & Inhibition & [102] \\
\hline & RXRa & S265 & Inhibition & [103] \\
\hline \multirow{2}{*}{ AMPK } & PPARa/PPPAR $\beta$ & thought activating p38/MAPK and ERK & Mix Effect depends on cell type & [104-106] \\
\hline & GR $\alpha$ & S211 through activating p38 & Inhibition & {$[107]$} \\
\hline $\begin{array}{l}\text { Other Postranstional } \\
\text { Modification }\end{array}$ & NR & Modification & Effect & Reference \\
\hline Multiple enzymes & Most NR & Acetylation & Activation & [108] \\
\hline \multirow{3}{*}{ SIRT1 } & ERa & deacetylase & Inhibition & {$[109,110]$} \\
\hline & PPARY & deacetylase & Inhibition & [110] \\
\hline & RAR & Deacetylase & Inhibition & [111] \\
\hline HDACs & Most NR & deacetylation & Mix effect & [108] \\
\hline
\end{tabular}

Table 1: Summary of major Posttranslational modifications that modulate nuclear receptors and have consequent effects on the function of biological clocks.

leads to period lengthening while using chemical compounds led to period shortening depend on the species and cell used, however both studies demonstrated the involvement of GSK-3 $\beta$ in clock regulation [66].

As GSK3 $\beta$ also phosphorylates the estrogen receptor $\alpha$ and REVERBa and to the contrary to Cry, this phostphorylation lead to protect the receptors from proteosomal degradation which ultimately lead to prolonging the transcriptional activity of these receptors (Table 1).

The cAMP signaling pathway is an internal component of the clock network. It is involved in transmitting the external signaling to the core oscillator to trigger rapid adaptive responses. AMPK has been shown to directly phosphorylate cryptochromes, Cry1 and Cry2 proteins and leads to their degradation [74]. In addition, cAMP can phosphorylate the CKIz at serine 389 and increase its enzymatic activity, which indirectly leads to Per2 destabilization [75]. In vivo it has been shown that activation of CAMPK by AICAR (5-aminoimidazole-4carboxyamide ribonucleoside) or metformin caused a shift in clock phase.

The cAMPK affect on clock proteins makes the biological clock sensitive to nutrition and metabolism. Beside phosphorylation, acetylation and sumolation, activities of certain proteins are also sensitive to nutritional signals.

In this regard, SIRT1 (silent mating type information regulation 2 homolog 1) with deactylase activity and another key metabolic sensor, has been reported to counteract the histone acetyltransferase (HAT) activity of CLOCK protein [76,77].

Similarly to SIRT1 which is a Class III HDAC and requires the coenzyme $\mathrm{NAD}^{+}$(nicotinamide adenine dinucleotide), Poly(ADPribose) polymerase 1 (PARP1), a second $\mathrm{NAD}^{+}$-dependent protein was recently shown to act as both a nutrient sensor and a modulator of clock function [78]. In the liver, PARP1 activity was found to be daytime dependent and probably driven by feeding rhythms rather than the local circadian clock since its cyclic activity persists in the absence of a functional liver clock. Further supporting this idea, the time of peak PARP1 activity was shifted in response to altering the time of food availability. Interestingly, PARP1 interacts with CLOCK and BMAL1, and was shown to ribosylate CLOCK in a rhythmic pattern [79]. PARP1 ${ }^{-1-}$ mice have altered circadian rhythms of locomotor activity and liver gene expression, clearly establishing a link between PARP1 and clock function.

Additionally the clock regulates the level of NAD in the cells, since 
the Nampt promoter (nicotinamide phosphoribosyl transferase), the rate-limiting enzyme in NAD biosynthesis is regulated by BMAL1. BMAL1 directly activates the Nampt promoter. Since SIRT1 is involved in BMAL1 and Clock deacytelation, this leads to another circadian feedback loop, an interaction between SIRT1 and Nampt that leads to the regulation of the SIRT1 cofactor, NAD through the inhibition of BMAL1/CLOCK complex activity [71].

The modification of histones through acetylation, deacetylation and phosphorylation is crucial for genome expression and regulation. In this respect, the CLOCK protein possesses an intrinsic histone acetyltransferase (HAT) activity that is essential for the activity of the molecular clock. CLOCK HAT activity acetylates the histone $\mathrm{H} 3$ in position lys14, which results in stimulation of gene expression of target genes. In addition, CLOCK acetylates its own partner BMAL1. For this action, the CLOCK: BMAL1 complex is assisted by the histone methytransferase MLL1 which directs the cyclic trimethylation of Histone 3/Lys4 of target promoters for subsequent acetylation [5].

The strong association of nuclear receptors to nutrition mobilization and regulation in the body make them susceptible to postranslational modification by these pathways as well. In fact, AMPK directly phosphorylates PPARa, PPAR $\beta$ and indirectly GRa as summarized in Table 1. In addition, SIRT1 has been shown to deacetylate estrogen alpha, PPAR $\gamma$ and RAR while GRa can be deacylated by HDAC2. Most of these modifications lead to the decrease of nuclear receptor activation; however the acetylation of ER alpha by P/CAF leads to its ligand sensitization (Table 1).

\section{The Interlink between the Clock, Nuclear Receptors and Cancer}

The majority of biochemical, behavioral and physiological processes are regulated rhythmically on daily cycles by endogenous 'clocks'. Regulation of the circadian clock is important for an organism's physiological function and behavior since it relies on it to anticipate and adapt to predictable daily changes such as day/night and activity/ rest cycles, metabolism, hormone secretion, insulin sensitivity, blood pressure and feeding time. The disruption of the circadian rhythms causes many diseases including sleep and mood disorders, diabetes, obesity and cancer [4].

It is well documented that sleep and activity rhythms are altered in cancer patients and these changes become more pronounced when anticancer drugs are administered at their most toxic time. This can accelerate cancer growth and shorten survival in the clinic. The interaction between the clock and cancer is further complicated by gender, clock genes mutations and drug type used. Many epidemiologic studies demonstrate a link between circadian disruption and cancer, shift work being an interesting example. The male shift workers have a significantly higher risk of prostate cancer [112]. Two important studies have involved around 120,000 nurses. One study was conducted with nurses younger than 55 years, and has found that extending the period of rotating night work was associated with a $36 \%$ risk of breast cancer, $35 \%$ colorectal cancer, $43 \%$ endometrial cancer independently from other known risk factors [113]. The second study involved female nurses younger than 42 years and established that the risk of breast cancer increased by $79 \%$ [114]. Based on these studies, the World Health Organization International Agency of Research on Cancer concluded that shift-work that leads to circadian disruption is probably carcinogenic for human [115].

The molecular mechanism linking the perturbation of the clock and tumor growth and survival is not very well understood. In mice deficient for Per2, the animals showed an increased risk of tumor development following exposure to ionizing radiation. The expression rates of Per1 and Per2 are lower in glioma cells when compared with non-malignant cells [116]. Over expression of Period in human cancer, cell lines increased their sensitivity to DNA damage and apoptosis; in contrast, down regulation of Period was associated with protection against ionizing radiation induced apoptosis [117,118]. In murine breast cancer models, the anti-apoptotic gene $\mathrm{Bcl} 2$ displayed a robust circadian oscillation in normal tissues, this rhythmicity was absent in the tumor itself [119].

Many studies have linked molecular clock components and the cell cycle machinery. A network of cyclin-dependent kinases (CDKs) governs the mammalian cell cycle. A different cyclin/Cdk complex controls each phase of the cell cycle: cyclin D/CDK4-6 and cyclin E/ CDK2 control G1 phase and the G1/S transition, respectively; cyclin $\mathrm{A} / \mathrm{CDK} 2$ allows progression into the $\mathrm{S}$ phase and DNA replication, while cyclin B/CDK1 involved in G2/M transition. Several lines of evidence at the cellular, whole organ and animal model levels showed that the cell cycle is gated by the biological clock at different points [120]. Firstly, the expression of Kinase Wee1, which inhibits the kinase CDK1 and blocks the G2/M transition, is directly regulated by BMAL. In addition, c-Myc, which promotes $\mathrm{G} 1$ cyclin synthesis, is inhibited by BMAL1while p21 and cyclin E is inhibited by REV-ERBa [121].

In addition to the cell cycle, several components of DNA damage and repair mechanisms are under circadian rhythm such as nucleotide excision repair; Tip60, a histone acetylase of chromatin, with DNA damage response and repair competency is regulated by the CLOCK/ BMAL1 [122].

These studies have directly linked the molecular clock to the cell cycle, chromatin remodeling and DNA repair, which can be disturbed in cancer. They also provide evidence that perturbation of the clock can be a major risk for cancer initiation and growth.

There is a second aspect to how malfunction of the clock can increase the risk of cancer, which is through the ability of the clock to regulate stem cells. In this regard, it is interesting to note that stem cells niches are composed of two populations based on the clock phases. Half of the population is at night phase and second half is at the day phase [123]. The two niches secrete either TGF- $\beta$ or Wnt, which have the opposite effect on cell division and differentiation, a mechanism that would guarantee a proper maintenance of stem cells in its pluripotent state. Once the stem cells are committed for differentiation, the balance gets shifted toward the TGF- $\beta$ pathway. This raises the question of how many other similar mechanisms are governed by the biological clock that is yet to be discovered. Many proteins and pathways that regulate the differentiation and status of stem cells also play an essential role in the function of the biological clock. For example, nuclear receptors such as those for glucocorticoids, estrogen and others that affect the clock also play an important role in adult and cancer stem cells fate. The involvement of histone acetylation and deacytelation in the regulation of stem cell differentiation is another aspect of its link to the clock. SIRT1 for example, can deacytelate the Per2 protein and disrupt the clock oscillation [124], and plays an important role in regulation of developmental genes during differentiation of stem cells. Sirt1 is involved in the development of various cancers such as prostate, breast and colorectal and chemotherapeutic drug resistance of cancer cells $[125,126]$.

The circadian oscillation of hematopoietic stem cell-derived 
Citation: Boudjelal M, Mosskowsaka DE, Farrow S (2013) Interlink between Nuclear Receptors, Posttranslational Modifications and the Biological Clock in Health and Diseases. J Carcinogene Mutagene S14: 005. doi:10.4172/2157-2518.S14-005

erythroid, myeloid, and lymphoid populations were demonstrated as well as those of circulating endothelial progenitor cells [127]. Svetvold and Laerum demonstrated that the circadian oscillation of hematopoietic lineages was age dependent such that the clock displayed a good rhythmicity in young mice but its amplitude and peak declined with age [128]. A similar profile has been reported in peripheral blood leukocytes [129]. Consistent with these observations, circulating levels of hematopoietic growth factors such as Granulocyte-Colony Stimulating Factor, Granulocyte-Monocyte Colony Stimulating Factor, Tumor Necrosis Factor, and Interleukins 2, 6, and 10 were also observed to display circadian oscillations [130-133]. In addition it has been suggested that the expression of stromal derived factor 1 (SDF1 or CXC12) is regulated by a signal from the suprachiasmatic nucleus $[134,135]$, thus it is likely that the expression profile of multiple growth factors, receptors, and related metabolic enzymes will exhibit circadian characteristics.

The circadian rhythmicity controlling the cell cycle and apoptotic pathways in hematopoietic cells and the disruption of the biological clock has been implicated in hematopoietic neoplasm [136]. Per2 deficient mice are known to have a 10 -fold increase of incidence of lymphomas when exposed to radiation. Moreover the cell cycle genes such cyclin D1 and A, c-Myc, Mdm2 and Gadd45a are deregulated in Per2 mutant mice [137]. In addition, the forced expression of Per1 and Per 2 in breast and prostate cancer cells inhibits their proliferation in culture, and inhibition of Per1 and Per2 by siRNA accelerates their proliferation [138]. The CLOCK and BMAL1 knock-out mice showed altered cell cycle dynamics and premature aging. In addition, they show tandem calcifications due possibly to abnormalities in the differentiation and function of the tandem stem cells $[139,140]$.

\section{Chronotherapy for Cancer Patients}

The discovery of the link between cancer and the clock, led many clinicans to consider chronotherapy, in which the anti-cancer drug is administrated at the optimal time and dose. If the chemotherapy is based on the fact the more the toxicity, the better outcome, in contrast chronotherapy showed that the lower the toxicity during treatment, the better outcome [141]. In many studies, the timing of cancer drug administration is rarely stipulated in the study protocols. Therefore, the time of dosing varies among patients and clinics and in most cases the drug is given during the day [142]. Taking into consideration that the drug targets and the pathways involved in cancer, and the drug metabolism and catabolism varies between day and night, chronotheraphy may provide an attractive approach to optimize treatment. As summarized in Figure 3, chemotherapy is based mainly upon the expectation that the clock controls the metabolism rate of drugs, apoptosis, angiogenesis and DNA repair mechanisms that are important elements in determining the pharmacokinetics and pharmacodynamics of a cytotoxic/cytostatic drug. Interferons (IFNs) are multifunctional cytokines that have antitumor activity, and their receptor shows a diurnal rhythm of expression in implanted tumor cells, showing the importance of considering optimal dosing times for IFN-b [143].

The toxicity of 40 anticancer drugs from different classes is affected by circadian timing in mice and rats. Interestingly the chronodosing of

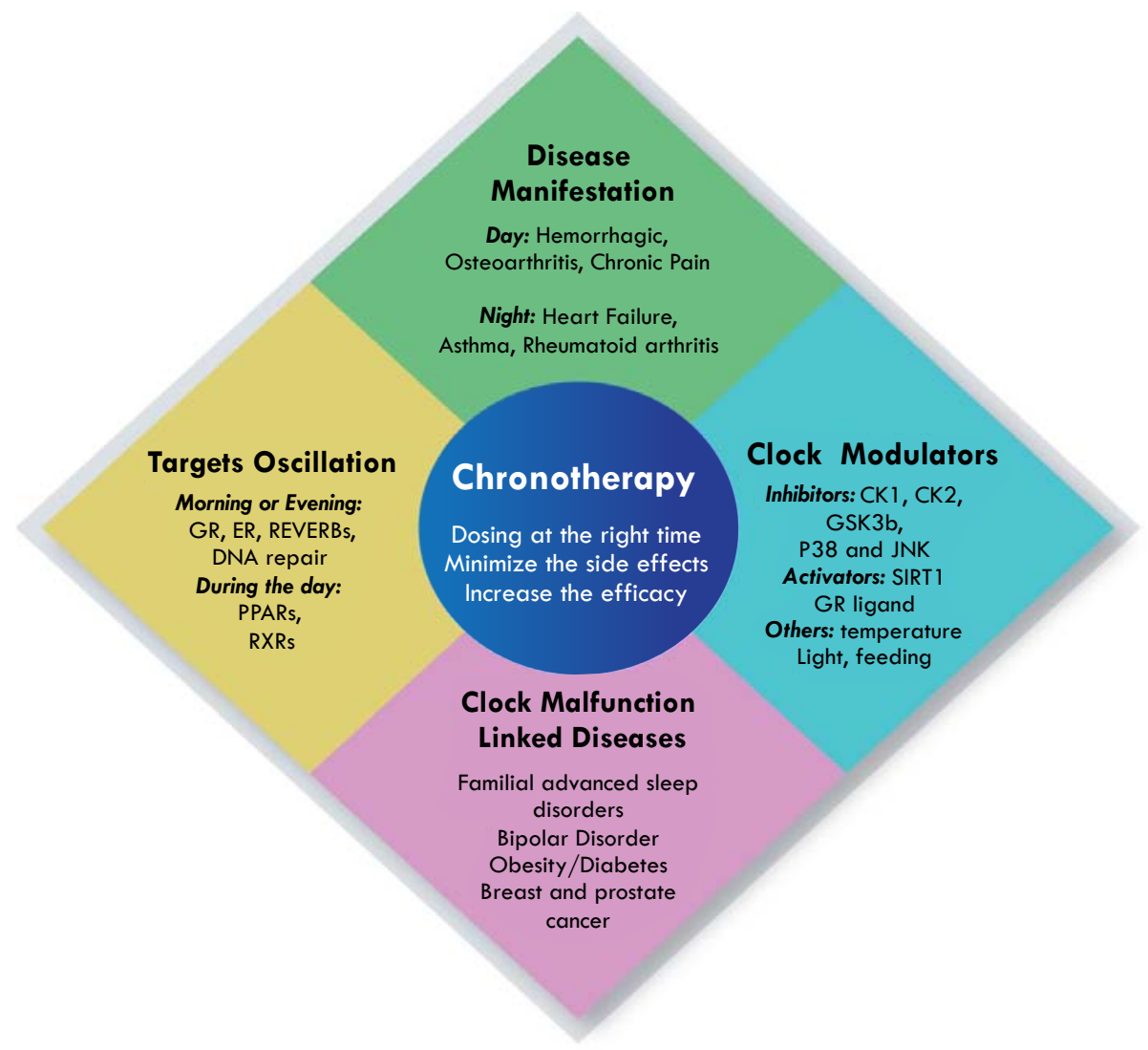

Figure 3: Factors demonstrating chronotherapy as an appropriate means to achieve optimum therapy in multiple diseases. 
anticancer drugs improved their tolerability up to five fold and efficacy up to two fold irrespective of their route of administration: orally, intravenous, intraperitoneal and intra-arterial. Furthermore, multiple Phase I, II and III trials of chronotherapeutic delivery in almost 2000 cases showed significant differences in efficacy and toxicity. Chronotherapy is facilitated by the fact the body clock can be measured with many biomarkers such as melatonin, cortizol, catacholomines, core temperature and rest-activity that remain stable even during most chemotherapy regimens. Several of these biomarkers are ameanable to measurement by external sensors [144].

The most detailed studies to demonstrate the usefulness of chronotherapy compared to standard treatment are for 5-flurouracil (5-FU), which is used against many types of solid tumors. This prodrug is activated in the cell and then inhibits thymidylate synthase to disturb DNA synthesis and repair, RNA processing which in turn disrupts cell metabolism and viability [145]. It has been determined that dosing 5-FU at very specific times of the circadian cycle is more efficient in killing tumor cells in patients as well as reducing its toxic affect. 5-FU is recommended to be given at $4 \mathrm{~h} 00$ which leads to a lower rate of subsequent hospital admissions due to severe adverse reactions, and lowers the proportion of patients withdrawing due to toxicity [146]. The activity of the dehydropyrimidine dehydrogenase in human mononuclear cells increases by $40 \%$ around midnight. This enzyme catabolizes 5-FUand improves tolerability. In contrast the tolerability of cisplatin is better between $16 \mathrm{~h} 00$ and $20 \mathrm{~h} 00$ and Oxaliplatin is given at 16h00 (Figure 4) [144].

In colorectal cancer chronomodulated infusion of 5-FU, leucovorin and Oxaliplatin for 4 days achieves similar survival when compared with conventional 2 day delivery of the same drugs and acceptable tolerability, with fewer incidences of diarrhea with $4 \mathrm{~d}$ delivery and neutopenia with $2 \mathrm{~d}$ delivery. Combination of cetuximab, a chimeric monoclonal antibody directed against the extracellular domain of epidermal growth factor, with circadian chronomodulated chemotherapy can be used effectively in initially resistant residual metastatic colorectal cancer [147]
The administration of cyclin dependent kinase inhibitors to tumor bearing animals has been shown to enhance the rhythmicity of clock genes in the tumors themselves. This has been associated with improved outcomes as shown by $>50 \%$ reduction in the extent of tumor growth [148]. Oncologists have begun to incorporate the emerging concepts of chronotherapy into their strategies for dosage administration [149]. These findings merit continued evaluation and research to better define the underlying mechanisms of circadian biology in cancer and cell proliferation.

The appropriate timing of conventionally formulated tablets and capsules and the use of special drug delivery systems to synchronize drug concentrations to rhythm in disease activity can accomplish Chronotherapy. In this regard chronotherapy can be administrated in non-hospitalized patients using special electronic pumps (Melodie) or an elastomeric pump with programmed electronic control of infusion flow rate (CIP). These pumps allow chronodelivery for up to four drugs over several days in outpatients [150]

\section{Role of Circadian Clock in Other Diseases}

\section{Circadian clock and metabolic diseases}

It is well documented that disruption of the clock leads to perturbation of glucose homeostasisin mammals and various clockgenes are associated with susceptibility to type 2 diabetes [151]. Moreover, the energy balance in the body is regulated by the hypothalamus and it is suggested that the clock in the hypothalamus neural network plays an important role in this function [152]. In the liver, which is the main site of metabolic action, at least $10 \%$ of its transcripts are rhythmic, allowing opposite reaction such as glycolysis/gluconeogenesis, lipogenesis/fatty acid oxidation to take place. For example the rate-limiting enzymes of glycolysis and gluconeogenesis oscillate and peak in the early morning and early evening respectively. Knock-out of BMAL1, Cry1 and Cry2 gene in the liver alters this oscillation [153]. The expression of the key liver enzyme phosphoenolpyruvate carboxylase (PEPCK) is at the cross roads of many clock regulators: its rhythmic expression is influenced by glucocorticoid, glucagon and is under the control of Crys as well as

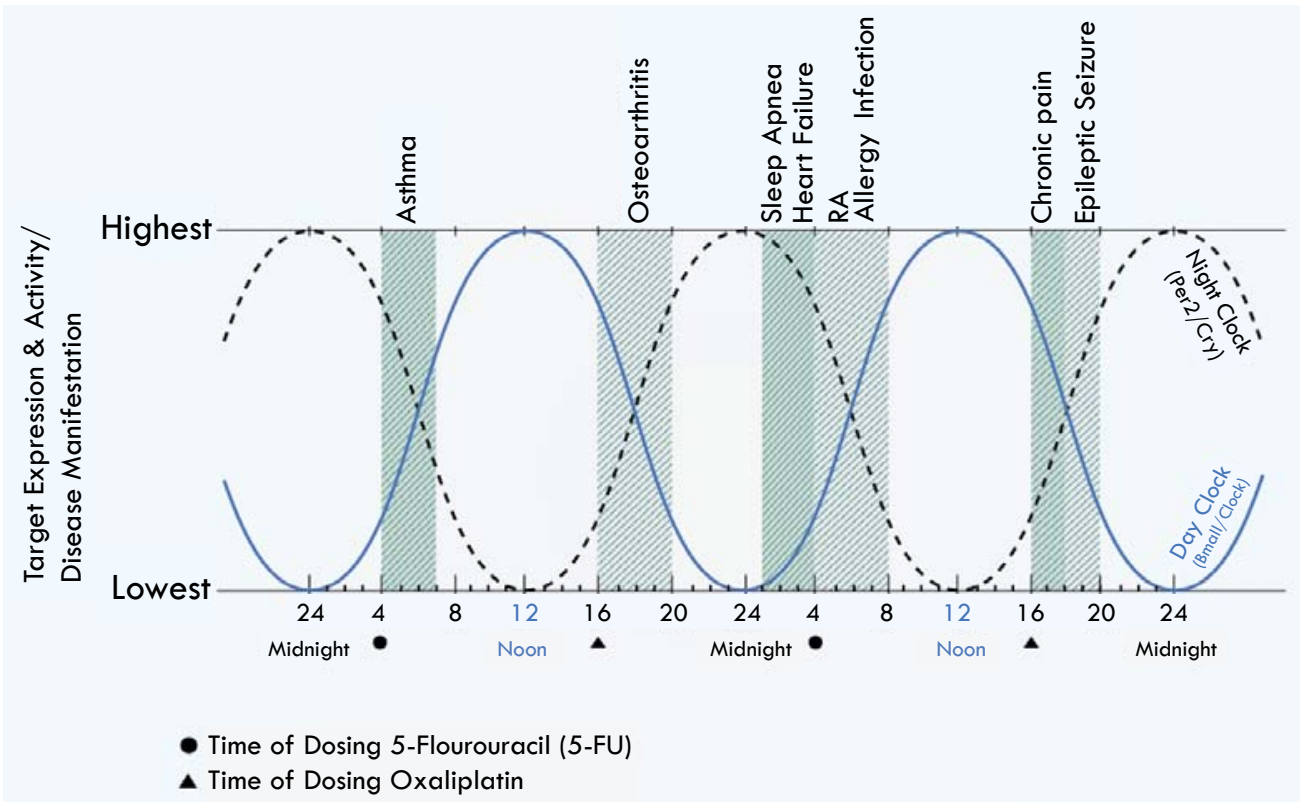

Figure 4: Time of manifestation of exemplar diseases during the day and night, and timing of the dosing of 5-Flourouracil and Oxaliplatin cancer drugs. 
REV-ERBa/ROR pair and PGC1-a [154]. Recent studies showed that shift work desynchronizes the body clock from environmental rhythms in part by perturbing the diurnal rhythm of PEPCK activity, causing impaired gluconeogenesis [155]. Moreover, the disruption of lipid metabolism in the liver leads to obesity and diabetes; in this regard, the role of PPARs is well documented to be essential for this function. The BMAL1 knock out fibroblast cannot differentiate into adipocyte and BMAL knock-out mice have an increased respiratory quotient and reduced fat storage [156]. Moreover, the dysfunction of the pancreas clock affects insulin secretion and glucose homeostasis.

As mentioned earlier, food and metabolites can synchronize the peripheral clock independently of the central clock. For example clock rhythms in the liver can entrain to a food restriction regime within two days even though SCN activity remains locked to light-dark cues throughout [157]. This implies that central and peripheral clock can be de-synchronized as result of lifestyles that oppose the natural circadian rhythms, a conclusion that has been demonstrated by a study in which human subjects were placed on 28 hours daily routine for 10 days [158]. In this study the body temperature of the volunteers remained at a 24 hour cycle while other biomarker such as leptin and insulin adhered to 28 hours based cycles. The perturbation leads to suppression of leptin, increase in glucose and hypertension exactly as has been observed in patients with chronic sleep deprivation.

Shift work represents chronic misalignment and it leads to resetting of the internal rhythm against environmental cycles. It is associated with obesity and metabolic disease. In this regard, it has been shown that limiting food access to the dark phase can effectively rescue the clock and metabolic dysfunction caused by shift work [159].

\section{Inflammation and the clock}

There is a strong link between circadian rhythm and inflammation pathways and diseases. For example patients with rheumatoid arthritis report daily variation in the severity of symptoms [160]. They experience greater joint pain, stiffness and functional disability in the morning [161]. At the molecular level, many studies have shown that the clock regulates the expression of multiple cytokines including IL6 [162]. The expression of the key pro-inflammatory cytokines IFN-g and IL-1B are reduced after LPS challenge in Per2 knock-out mice [163]. In addition, the down regulation of BMAL by siRNA in macrophages reduces the cytokine expression and NF- $\kappa B$ pathway activity [163]. It also has been demonstrated that the expression of IL6 is under the control on REVERBa in human macrophages. This study demonstrated that REV$\mathrm{ERB} \alpha$ as the key link between the clock and immune function [164].

Asthma patient who experience nocturnal symptoms, have nighttime exacerbations partially driven by an increase in bronchial responsiveness. Inhaled glucocorticoids are used to inhibit asthma inflammation and 32 -andrenoceptor agonists are used to block airway obstruction in the respiratory tract in asthma patients [165]. The ability of glucocorticoid and $\beta$-adrenorceptor agonists to regulate the clock through modulating the expression of Per1 and also the transcription factors and kinases involved in clock regulation such as MAPK and CREB may also be important [166]. The chronodosing of asthma drugs is now widely practiced and in this regard, specific delivery systems have been developed to deliver chronotherapeutics. For example, Ciclesonide, a novel glucocorticoid that is hydrolyzed by esterases to form the active metabolite in the patient is administrated once daily at night. The generated metabolite desibobutyryl-ciclesonide exhibits 100-fold greater affinity to the glucocorticoid receptor. In addition, prednisone and methylprednisolone are more effective when administrated at $15 \mathrm{~h} 00$ compared to other times of the day or night. However, more work is needed to dissect the molecular mechanisms by which the clock affects asthma as well as how the drugs themselves affect the clock and verse-versa [167].

\section{Mood disorders and the clock}

Important neurological diseases such as major depressive disorder (MDD), bipolar disorder (BD) and sleep deprivation are highly linked to circadian clock perturbation in the SCN [168]. These diseases are characterized by depressed mood, perturbation of goal directed activity, sleep deprivation, loss of cognition ability and appetite. In MDD the clock has been reported to be phase delayed, the level of the delay is associated with the severity of the depression [169]. Another study found that the clock has lower amplitude in depressed patients [170] and similar studies would be instructive in BD patients. The RORa mutation has been associated with depression in genetic studies [171]. Per2 deficient mice show reduced monoamine oxidase A, increased dopamine in the brain and also reduced depression and anxiety-like behaviors, similarly RORa knock-out mice have reduced depression and anxiety-like behaviors [172,173]. Many drugs used to treat mood disorders affect the clock such as the antidepressant fluoxetine, which advances SCN phase. Others shorten the circadian period and lithium delays phase and increases Per2 amplitude. At the molecular level, lithium inhibits GSK3 $\beta$, which phosphorylates the BMAL1, Per2 and REV-ERBa clock proteins [174].

Sleep disorder is associated with clock malfunction of the clock and this includes sleep apnea and familial advanced sleep phase syndrome (FASPS) disorders. The former is more evident during the night, and the FASPS is caused by mutations in Per2 and associated kinases, CKI $3 / \mathrm{Q}[175]$.

\section{Concluding Remarks}

Correct function of the biological clock is crucial to insure that the body's physiological pathways are synchronised and work in phase. It regulates the cell cycle, immune system, and stem cell differentiation and growth pathways. The desynchronization of the central and peripheral clock cause many $21^{\text {st }}$ century disorders, including obesity, diabetes, cancer and aging.

The functionality of the biological clock is highly regulated by complex transcription factors and posttranslational modifications, and therefore any dysfunction of these networks will have profound consequences on downstream biology and consequently cause severe health problems. As many novel and next generation drugs target transcriptional regulation such as nuclear receptors modulators, kinases inhibitors and epigenetic regulating enzymes, careful consideration should be given to the time and duration of activation of these pathways, and hence designing a proper treatment protocol based on clock biology. In this regard, chronotherapy has been proven to be effective in many diseases such as Asthma, rheumatoid arthritis and cancer. As summarized in Figure 4, chronotherapy takes into consideration the timing of target expression, disease manifestation and the activation of the enzymatic machinery involved in drug metabolism. Figure 4 summarizes the timing of the manifestation of several common diseases.

Chronotherapy provides an alternative approach for drug discovery and development as well as potentially repositioning those compounds that are metabolically cleared very fast even though may be very potent inhibitors or modulators of their targets. As the clock regulates over $10 \%$ of the genome, with the high demand to develop 
Citation: Boudjelal M, Mosskowsaka DE, Farrow S (2013) Interlink between Nuclear Receptors, Posttranslational Modifications and the Biological Clock in Health and Diseases. J Carcinogene Mutagene S14: 005. doi:10.4172/2157-2518.S14-005

more effective and safer drugs, chronotherapy may be one of the most effective approaches to achieve this aim and become commonplace in clinical practice in the future.

\section{Acknowledgement}

The authors would like to thank Ms Maha Al-Ammar and Ms Joanna May Aranas for graphic design and administrative assistance and Dr Mohamed Al Jumah, KAIMRC Executive Director for his support.

\section{References}

1. Relógio A, Westermark PO, Wallach T, Schellenberg K, Kramer A, et al. (2011) Tuning the mammalian circadian clock: robust synergy of two loops. PLoS Comput Biol 7: e1002309.

2. Akhtar RA, Reddy AB, Maywood ES, Clayton JD, King VM, et al. (2002) Circadian cycling of the mouse liver transcriptome, as revealed by cDNA microarray, is driven by the suprachiasmatic nucleus. Curr Biol 12: 540-550.

3. Panda S, Antoch MP, Miller BH, Su Al, Schook AB, et al. (2002) Coordinated transcription of key pathways in the mouse by the circadian clock. Cell 109: 307-320

4. Loudon AS (2012) Circadian biology: a 2.5 billion year old clock. Curr Biol 22: R570-571.

5. Masri S, Zocchi L, Katada S, Mora E, Sassone-Corsi P (2012) The circadian clock transcriptional complex: metabolic feedback intersects with epigenetic control. Ann N Y Acad Sci 1264: 103-109.

6. Buhr ED, Yoo SH, Takahashi JS (2010) Temperature as a universal resetting cue for mammalian circadian oscillators. Science 330: 379-385.

7. Chaudhury D, Wang LM, Colwell CS (2005) Circadian regulation of hippocampal long-term potentiation. J Biol Rhythms 20: 225-236.

8. Masri S, Sassone-Corsi P (2013) The circadian clock: a framework linking metabolism, epigenetics and neuronal function. Nat Rev Neurosci 14: 69-75.

9. Levi F, Schibler U (2007) Circadian rhythms: mechanisms and therapeutic implications. Annu Rev Pharmacol Toxicol 47: 593-628.

10. Vanselow K, Vanselow JT, Westermark PO, Reischl S, Maier B, et al. (2006) Differential effects of PER2 phosphorylation: molecular basis for the human familial advanced sleep phase syndrome (FASPS). Genes Dev 20: 2660-2672.

11. Takahashi JS, Hong HK, Ko CH, McDearmon EL (2008) The genetics of mammalian circadian order and disorder: implications for physiology and disease. Nat Rev Genet 9: 764-775

12. Ptácek LJ, Jones CR, Fu YH (2007) Novel insights from genetic and molecular characterization of the human clock. Cold Spring Harb Symp Quant Biol 72 : 273-277.

13. Marcheva B, Ramsey KM, Buhr ED, Kobayashi Y, Su H, et al. (2010) Disruption of the clock components CLOCK and BMAL1 leads to hypoinsulinaemia and diabetes. Nature 466: 627-631.

14. Gronemeyer H, Gustafsson JA, Laudet V (2004) Principles for modulation of the nuclear receptor superfamily. Nat Rev Drug Discov 3: 950-964.

15. Roenneberg T, Merrow M (2005) Circadian clocks - the fall and rise of physiology. Nat Rev Mol Cell Biol 6: 965-971.

16. Dunlap JC (1999) Molecular bases for circadian clocks. Cell 96: 271-290.

17. Gery S, Koeffler HP (2010) Circadian rhythms and cancer. Cell Cycle 9: 10971103.

18. Zhang EE, Kay SA (2010) Clocks not winding down: unravelling circadian networks. Nat Rev Mol Cell Biol 11: 764-776.

19. Schmutz I, Ripperger JA, Baeriswyl-Aebischer S, Albrecht U (2010) The mammalian clock component PERIOD2 coordinates circadian output by interaction with nuclear receptors. Genes Dev 24: 345-357.

20. Duez H, Staels B (2008) The nuclear receptors Rev-erbs and RORs integrate circadian rhythms and metabolism. Diab Vasc Dis Res 5: 82-88.

21. Carlberg C, Hooft van Huijsduijnen R, Staple JK, De Lamarter JF, BeckerAndré M (1994) RZRs, a new family of retinoid-related orphan receptors that function as both monomers and homodimers. Mol Endocrinol 8: 757-770.

22. Hirose T, Smith RJ, Jetten AM (1994) ROR gamma: the third member of ROR/
RZR orphan receptor subfamily that is highly expressed in skeletal muscle. Biochem Biophys Res Commun 205: 1976-1983.

23. Jetten AM (2009) Retinoid-related orphan receptors (RORs): critical roles in development, immunity, circadian rhythm, and cellular metabolism. Nucl Recept Signal 7: e003.

24. Harding HP, Lazar MA (1995) The monomer-binding orphan receptor Rev-Erb represses transcription as a dimer on a novel direct repeat. Mol Cell Biol 15 4791-4802.

25. Guillaumond F, Dardente H, Giguère V, Cermakian N (2005) Differential contro of Bmal1 circadian transcription by REV-ERB and ROR nuclear receptors. $J$ Biol Rhythms 20: 391-403.

26. Sato TK, Panda S, Miraglia LJ, Reyes TM, Rudic RD, et al. (2004) A functional genomics strategy reveals Rora as a component of the mammalian circadian clock. Neuron 43: 527-537.

27. Akashi M, Takumi T (2005) The orphan nuclear receptor RORalpha regulates circadian transcription of the mammalian core-clock Bmal1. Nat Struct Mol Bio 12: $441-448$.

28. Solt LA, Kojetin DJ, Burris TP (2011) The REV-ERBs and RORs: molecula links between circadian rhythms and lipid homeostasis. Future Med Chem 3 623-638.

29. Yang X, Lamia KA, Evans RM (2007) Nuclear receptors, metabolism, and the circadian clock. Cold Spring Harb Symp Quant Biol 72: 387-394.

30. McKenna NJ, Cooney AJ, DeMayo FJ, Downes M, Glass CK, et al. (2009) Minireview: Evolution of NURSA, the Nuclear Receptor Signaling Atlas. Mo Endocrinol 23: 740-746.

31. Warnecke M, Oster H, Revelli JP, Alvarez-Bolado G, Eichele G (2005) Abnormal development of the locus coeruleus in Ear2(Nr2f6)-deficient mice impairs the functionality of the forebrain clock and affects nociception. Genes Dev 19: 614-625.

32. Dkhissi-Benyahya O, Gronfier C, De Vanssay W, Flamant F, Cooper HM (2007) Modeling the role of mid-wavelength cones in circadian responses to light. Neuron 53: 677-687.

33. Navigatore-Fonzo LS, Golini RL, Ponce IT, Delgado SM, Plateo-Pignatar MG, et al. (2013) Retinoic acid receptors move in time with the clock in the hippocampus. Effect of a vitamin-A-deficient diet. J Nutr Biochem 24: 859-867.

34. Shirai H, Oishi K, Ishida N (2006) Circadian expression of clock genes is maintained in the liver of Vitamin A-deficient mice. Neurosci Lett 398: 69-72.

35. McNamara P, Seo SB, Rudic RD, Sehgal A, Chakravarti D, et al. (2001) Regulation of CLOCK and MOP4 by nuclear hormone receptors in the vasculature: a humoral mechanism to reset a peripheral clock. Cell 105: $877-$ 889 .

36. Dickmeis T (2009) Glucocorticoids and the circadian clock. J Endocrinol 200: 3-22.

37. Yamazaki S, Numano R, Abe M, Hida A, Takahashi R, et al. (2000) Resetting central and peripheral circadian oscillators in transgenic rats. Science 288 682-685.

38. Kino T, Su YA, Chrousos GP (2009) Human glucocorticoid receptor isoform beta: recent understanding of its potential implications in physiology and pathophysiology. Cell Mol Life Sci 66: 3435-3448.

39. Miner JN, Yamamoto KR (1991) Regulatory crosstalk at composite response elements. Trends Biochem Sci 16: 423-426.

40. Kino T, Ichijo T, Amin ND, Kesavapany S, Wang Y, et al. (2007) Cyclindependent kinase 5 differentially regulates the transcriptional activity of the glucocorticoid receptor through phosphorylation: clinical implications for the nervous system response to glucocorticoids and stress. Mol Endocrinol 21 1552-1568.

41. Nader N, Chrousos GP, Kino T (2010) Interactions of the circadian CLOCK system and the HPA axis. Trends Endocrinol Metab 21: 277-286.

42. Balsalobre A, Marcacci L, Schibler U (2000) Multiple signaling pathways elicit circadian gene expression in cultured Rat-1 fibroblasts. Curr Biol 10: 12911294.

43. Robinson-Rechavi M, Escriva Garcia H, Laudet V (2003) The nuclear receptor superfamily. J Cell Sci 116: 585-586.

44. Métivier R, Penot G, Hübner MR, Reid G, Brand H, et al. (2003) Estrogen 
Citation: Boudjelal M, Mosskowsaka DE, Farrow S (2013) Interlink between Nuclear Receptors, Posttranslational Modifications and the Biological Clock in Health and Diseases. J Carcinogene Mutagene S14: 005. doi:10.4172/2157-2518.S14-005

receptor-alpha directs ordered, cyclical, and combinatorial recruitment of cofactors on a natural target promoter. Cell 115: 751-763.

45. Chen ST, Choo KB, Hou MF, Yeh KT, Kuo SJ, et al. (2005) Deregulated expression of the PER1, PER2 and PER3 genes in breast cancers. Carcinogenesis 26: 1241-1246.

46. Metz RP, Qu X, Laffin B, Earnest D, Porter WW (2006) Circadian clock and cell cycle gene expression in mouse mammary epithelial cells and in the developing mouse mammary gland. Dev Dyn 235: 263-271.

47. Gery S, Virk RK, Chumakov K, Yu A, Koeffler HP (2007) The clock gene Per2 links the circadian system to the estrogen receptor. Oncogene 26: 7916-7920.

48. Rossetti S, Esposito J, Corlazzoli F, Gregorski A, Sacchi N (2012) Entrainment of breast (cancer) epithelial cells detects distinct circadian oscillation patterns for clock and hormone receptor genes. Cell Cycle 11: 350-360.

49. Li S, Wang M, Ao X, Chang AK, Yang C, et al. (2012) CLOCK is a substrate of SUMO and sumoylation of CLOCK upregulates the transcriptional activity of estrogen receptor-Ît Oncogene

50. Shimizu T, Hirai Y, Murayama C, Miyamoto A, Miyazaki H, et al. (2011) Circadian Clock genes Per2 and clock regulate steroid production, cell proliferation, and luteinizing hormone receptor transcription in ovarian granulosa cells. Biochem Biophys Res Commun 412: 132-135.

51. Mendoza J, Gourmelen S, Dumont S, Sage-Ciocca D, Pévet P, et al. (2012) Setting the main circadian clock of a diurnal mammal by hypocaloric feeding. $J$ Physiol 590: 3155-3168.

52. Varga T, Czimmerer Z, Nagy L (2011) PPARs are a unique set of fatty acid regulated transcription factors controlling both lipid metabolism and inflammation. Biochim Biophys Acta 1812: 1007-1022.

53. Michalik L, Auwerx J, Berger JP, Chatterjee VK, Glass CK, et al. (2006) International Union of Pharmacology. LXI. Peroxisome proliferator-activated receptors. Pharmacol Rev 58: 726-741.

54. Kersten S (2010) Regulation of nutrient metabolism and inflammation. Results Probl Cell Differ 52: 13-25.

55. Delerive P, De Bosscher K, Vanden Berghe W, Fruchart JC, Haegeman G, et al (2002) DNA binding-independent induction of IkappaBalpha gene transcription by PPARalpha. Mol Endocrinol 16: 1029-1039.

56. Stienstra R, Mandard S, Tan NS, Wahli W, Trautwein C, et al. (2007) The Interleukin-1 receptor antagonist is a direct target gene of PPARalpha in liver. J Hepatol 46: 869-877.

57. Wahli W, Michalik L (2012) PPARs at the crossroads of lipid signaling and inflammation. Trends Endocrinol Metab 23: 351-363.

58. Charoensuksai P, Xu W (2010) PPARs in Rhythmic Metabolic Regulation and Implications in Health and Disease. PPAR Res 2010

59. Nakamura K, Inoue I, Takahashi S, Komoda T, Katayama S (2008) Cryptochrome and Period Proteins Are Regulated by the CLOCK/BMAL1 Gene: Crosstalk between the PPARs/RXRalpha-Regulated and CLOCK/ BMAL1-Regulated Systems. PPAR Res 2008: 348610.

60. Canaple L, Rambaud J, Dkhissi-Benyahya O, Rayet B, Tan NS, et al. (2006) Reciprocal regulation of brain and muscle Arnt-like protein 1 and peroxisome proliferator-activated receptor a defines a novel positive feedback loop in the rodent liver circadian clock. Molecular Endocrinology 20: 1715-1727.

61. Gatfield D, Le Martelot G, Vejnar CE, Gerlach D, Schaad O, et al. (2009) Integration of microRNA miR-122 in hepatic circadian gene expression. Genes Dev 23: 1313-1326.

62. Wang N, Yang G, Jia Z, Zhang H, Aoyagi T, et al. (2008) Vascular PPARgamma controls circadian variation in blood pressure and heart rate through Bmal1. Cell Metab 8: 482-491.

63. Yu S, Reddy JK (2007) Transcription coactivators for peroxisome proliferatoractivated receptors. Biochim Biophys Acta 1771: 936-951.

64. Liu C, Li S, Liu T, Borjigin J, Lin JD (2007) Transcriptional coactivator PGC1alpha integrates the mammalian clock and energy metabolism. Nature 447: 477-481.

65. Cho H, Zhao X, Hatori M, Yu RT, Barish GD, et al. (2012) Regulation of circadian behaviour and metabolism by REV-ERB-Î̀ and REV-ERB-Î́2. Nature 485: $123-127$.
66. Reischl S, Kramer A (2011) Kinases and phosphatases in the mammalian circadian clock. FEBS Lett 585: 1393-1399.

67. Meng QJ, Logunova L, Maywood ES, Gallego M, Lebiecki J, et al. (2008) Setting clock speed in mammals: the CK1 epsilon tau mutation in mice accelerates circadian pacemakers by selectively destabilizing PERIOD proteins. Neuron 58: 78-88

68. Xu Y, Padiath QS, Shapiro RE, Jones CR, Wu SC, et al. (2005) Functiona consequences of a CKIdelta mutation causing familial advanced sleep phase syndrome. Nature 434: 640-644.

69. Tsuchiya Y, Akashi M, Matsuda M, Goto K, Miyata Y, et al. (2009) Involvement of the protein kinase CK2 in the regulation of mammalian circadian rhythms. Sci Signal 2: ra26.

70. Zhang L, Abraham D, Lin ST, Oster H, Eichele G, et al. (2012) PKCî participates in food entrainment by regulating BMAL1. Proc Natl Acad Sci U S A 109: 20679-20684.

71. Uchida Y, Osaki T, Yamasaki T, Shimomura T, Hata S, et al. (2012) Involvement of stress kinase mitogen-activated protein kinase kinase 7 in regulation of mammalian circadian clock. J Biol Chem 287: 8318-8326.

72. Li J, Lu WQ, Beesley S, Loudon AS, Meng QJ (2012) Lithium impacts on the amplitude and period of the molecular circadian clockwork. PLoS One 7: e33292.

73. Harada Y, Sakai M, Kurabayashi N, Hirota T, Fukada Y (2005) Ser-557 phosphorylated mCRY2 is degraded upon synergistic phosphorylation by glycogen synthase kinase-3 beta. J Biol Chem 280: 31714-31721.

74. Lamia KA, Sachdeva UM, DiTacchio L, Williams EC, Alvarez JG, et al. (2009) AMPK regulates the circadian clock by cryptochrome phosphorylation and degradation. Science 326: 437-440

75. Um JH, Yang S, Yamazaki S, Kang H, Viollet B, et al. (2007) Activation of 5'-AMP-activated kinase with diabetes drug metformin induces casein kinase lepsilon (CKlepsilon)-dependent degradation of clock protein mPer2. J Biol Chem 282: 20794-20798.

76. Asher G, Gatfield D, Stratmann M, Reinke H, Dibner C, et al. (2008) SIRT regulates circadian clock gene expression through PER2 deacetylation. Cell 134: 317-328.

77. Nakahata Y, Kaluzova M, Grimaldi B, Sahar S, Hirayama J, et al. (2008) The NAD+-dependent deacetylase SIRT1 modulates CLOCK-mediated chromatin remodeling and circadian control. Cell 134: 329-340.

78. D'Amours D, Desnoyers S, D'Silva I, Poirier GG (1999) Poly(ADP-ribosyl)ation reactions in the regulation of nuclear functions. Biochem J $342: 249-268$.

79. Asher G, Reinke H, Altmeyer M, Gutierrez-Arcelus M, Hottiger MO, et al. (2010) Poly(ADP-ribose) polymerase 1 participates in the phase entrainment of circadian clocks to feeding. Cell 142: 943-953.

80. Gray JP, Burns KA, Leas TL, Perdew GH, Vanden Heuvel JP (2005) Regulation of peroxisome proliferator-activated receptor alpha by protein kinase C. Biochemistry 44: 10313-10321.

81. Williams CC, Basu A, El-Gharbawy A, Carrier LM, Smith CL, et al. (2009) Identification of four novel phosphorylation sites in estrogen receptor alpha: impact on receptor-dependent gene expression and phosphorylation by protein kinase CK2. BMC Biochem 10: 36.

82. Delmotte MH, Tahayato A, Formstecher P, Lefebvre P (1999) Serine 157, a retinoic acid receptor alpha residue phosphorylated by protein kinase $\mathrm{C}$ in vitro, is involved in RXR.RARalpha heterodimerization and transcriptional activity. Biol Chem 274: 38225-38231.

83. Duplus E, Gras C, Soubeyre V, Vodjdani G, Lemaigre-Dubreuil Y, et al. (2008) Phosphorylation and transcriptional activity regulation of retinoid-related orphan receptor alpha 1 by protein kinases C. J Neurochem 104: 1321-1332.

84. Lazennec G, Canaple L, Saugy D, Wahli W (2000) Activation of peroxisome proliferator-activated receptors (PPARs) by their ligands and protein kinase A activators. Mol Endocrinol 14: 1962-1975.

85. de Leeuw R, Neefjes J, Michalides R (2011) A role for estrogen recepto phosphorylation in the resistance to tamoxifen. Int J Breast Cancer 2011 232435

86. Chen D, Pace PE, Coombes RC, Ali S (1999) Phosphorylation of human estrogen receptor alpha by protein kinase $\mathrm{A}$ regulates dimerization. Mol Cell Biol 19: 1002-1015. 
Citation: Boudjelal M, Mosskowsaka DE, Farrow S (2013) Interlink between Nuclear Receptors, Posttranslational Modifications and the Biological Clock in Health and Diseases. J Carcinogene Mutagene S14: 005. doi:10.4172/2157-2518.S14-005

87. Rochette-Egly C, Plassat JL, Taneja R, Chambon P (2000) The AF-1 and AF-2 activating domains of retinoic acid receptor-alpha (RARalpha) and their phosphorylation are differentially involved in parietal endodermal differentiation of F9 cells and retinoid-induced expression of target genes. Mol Endocrinol 14: 1398-1410.

88. Taneja R, Rochette-Egly C, Plassat JL, Penna L, Gaub MP, et al. (1997) Phosphorylation of activation functions AF-1 and AF-2 of RAR alpha and RAR gamma is indispensable for differentiation of F9 cells upon retinoic acid and cAMP treatment. EMBO J 16: 6452-6465.

89. von Knethen A, Tzieply N, Jennewein C, Brüne B (2010) Casein-kinaseII-dependent phosphorylation of PPARgamma provokes CRM1-mediated shuttling of PPARgamma from the nucleus to the cytosol. J Cell Sci 123: 192201.

90. Medunjanin S, Hermani A, De Servi B, Grisouard J, Rincke G, et al. (2005) Glycogen synthase kinase-3 interacts with and phosphorylates estrogen receptor alpha and is involved in the regulation of receptor activity. J Biol Chem 280: 33006-33014

91. Yin L, Wang J, Klein PS, Lazar MA (2006) Nuclear receptor Rev-erbalpha is a critical lithium-sensitive component of the circadian clock. Science 311: 1002 1005.

92. Duncan JG, Bharadwaj KG, Fong JL, Mitra R, Sambandam N, et al. (2010) Rescue of cardiomyopathy in peroxisome proliferator-activated receptoralpha transgenic mice by deletion of lipoprotein lipase identifies sources of cardiac lipids and peroxisome proliferator-activated receptor-alpha activators. Circulation 121: 426-435.

93. Driggers PH, Segars JH, Rubino DM (2001) The proto-oncoprotein Brx activates estrogen receptor beta by a p38 mitogen-activated protein kinase pathway. J Biol Chem 276: 46792-46797.

94. Miller AL, Webb MS, Copik AJ, Wang Y, Johnson BH, et al. (2005) p38 Mitogen-activated protein kinase (MAPK) is a key mediator in glucocorticoidinduced apoptosis of lymphoid cells: correlation between p38 MAPK activation and site-specific phosphorylation of the human glucocorticoid receptor at serine 211. Mol Endocrinol 19: 1569-1583.

95. Giannì M, Bauer A, Garattini E, Chambon P, Rochette-Egly C (2002) Phosphorylation by p38MAPK and recruitment of SUG-1 are required for RAinduced RAR gamma degradation and transactivation. EMBO J 21: 3760-3769.

96. Shao D, Rangwala SM, Bailey ST, Krakow SL, Reginato MJ, et al. (1998) Interdomain communication regulating ligand binding by PPAR-gamma. Nature 396: $377-380$.

97. Kato S, Endoh H, Masuhiro Y, Kitamoto T, Uchiyama S, et al. (1995) Activation of the estrogen receptor through phosphorylation by mitogen-activated protein kinase. Science 270: 1491-1494.

98. Ismaili N, Garabedian MJ (2004) Modulation of glucocorticoid receptor function via phosphorylation. Ann N Y Acad Sci 1024: 86-101.

99. Juge-Aubry CE, Hammar E, Siegrist-Kaiser C, Pernin A, Takeshita A, et al. (1999) Regulation of the transcriptional activity of the peroxisome proliferatoractivated receptor alpha by phosphorylation of a ligand-independent transactivating domain. J Biol Chem 274: 10505-10510.

100.Adams M, Reginato MJ, Shao D, Lazar MA, Chatterjee VK (1997) Transcriptional activation by peroxisome proliferator-activated receptor gamma is inhibited by phosphorylation at a consensus mitogen-activated protein kinase site. J Biol Chem 272: 5128-5132.

101. Lechtken A, Hörnig M, Werz O, Corvey N, Zündorf I, et al. (2007) Extracellular signal-regulated kinase-2 phosphorylates RORalpha4 in vitro. Biochem Biophys Res Commun 358: 890-896.

102.Lee HY, Suh YA, Robinson MJ, Clifford JL, Hong WK, et al. (2000) Stress pathway activation induces phosphorylation of retinoid $\mathrm{X}$ receptor. $\mathrm{J}$ Biol Chem 275: 32193-32199.

103. Matsushima-Nishiwaki R, Okuno M, Adachi S, Sano T, Akita K, et al. (2001) Phosphorylation of retinoid $X$ receptor alpha at serine 260 impairs its metabolism and function in human hepatocellular carcinoma. Cancer Res 61: 7675-7682.

104. Sozio MS, Lu C, Zeng Y, Liangpunsakul S, Crabb DW (2011) Activated AMPK inhibits PPAR-\{alpha\} and PPAR-\{gamma\} transcriptional activity in hepatoma cells. Am J Physiol Gastrointest Liver Physiol 301: G739-747.

105. Gan Z, Burkart-Hartman EM, Han DH, Finck B, Leone TC, et al. (2011)
The nuclear receptor PPARÎ2 $\hat{I}^{\prime}$ programs muscle glucose metabolism in cooperation with AMPK and MEF2. Genes Dev 25: 2619-2630.

106. Meng R, Pei Z, Zhang A, Zhou Y, Cai X, et al. (2011) AMPK activation enhances PPARİ activity to inhibit cardiac hypertrophy via ERK1/2 MAPK signaling pathway. Arch Biochem Biophys 511: 1-7.

107.Nader N, Ng SS, Lambrou GI, Pervanidou P, Wang Y, et al. (2010) AMPK regulates metabolic actions of glucocorticoids by phosphorylating the glucocorticoid receptor through p38 MAPK. Mol Endocrinol 24: 1748-1764.

108. Anbalagan M, Huderson B, Murphy L, Rowan BG (2012) Post-translational modifications of nuclear receptors and human disease. Nucl Recept Signal 10: e001.

109. Gopalakrishna R, Jaken S (2000) Protein kinase C signaling and oxidative stress. Free Radic Biol Med 28: 1349-1361.

110. Berrabah W, Aumercier P, Lefebvre P, Staels B (2011) Control of nuclear receptor activities in metabolism by post-translational modifications. FEBS Lett 585: 1640-1650.

111. Kang MR, Lee SW, Um E, Kang HT, Hwang ES, et al. (2010) Reciprocal roles of SIRT1 and SKIP in the regulation of RAR activity: implication in the retinoic acid-induced neuronal differentiation of P19 cells. Nucleic Acids Res 38: 822 831.

112. Kubo T, Ozasa K, Mikami K, Wakai K, Fujino Y, et al. (2006) Prospective cohort study of the risk of prostate cancer among rotating-shift workers: findings from the Japan collaborative cohort study. Am J Epidemiol 164: 549-555.

113. Schernhammer ES, Laden F, Speizer FE, Willett WC, Hunter DJ, et al. (2001) Rotating night shifts and risk of breast cancer in women participating in the nurses' health study. J Natl Cancer Inst 93: 1563-1568.

114. Megdal SP, Kroenke CH, Laden F, Pukkala E, Schernhammer ES (2005) Night work and breast cancer risk: a systematic review and meta-analysis. Eur J Cancer 41: 2023-2032.

115. Straif K, Baan R, Grosse Y, Secretan B, El Ghissassi F, et al. (2007) Carcinogenicity of shift-work, painting, and fire-fighting. Lancet Oncol 8: 1065 1066 .

116. Xia HC, Niu ZF, Ma H, Cao SZ, Hao SC, et al. (2010) Deregulated expression of the Per1 and Per2 in human gliomas. Can J Neurol Sci 37: 365-370.

117. Fu L, Patel MS, Bradley A, Wagner EF, Karsenty G (2005) The molecular clock mediates leptin-regulated bone formation. Cell 122: 803-815.

118. Gery S, Koeffler HP (2007) The role of circadian regulation in cancer. Cold Spring Harb Symp Quant Biol 72: 459-464.

119. Granda TG, Liu XH, Smaaland R, Cermakian N, Filipski E, et al. (2005) Circadian regulation of cell cycle and apoptosis proteins in mouse bone marrow and tumor. FASEB J 19: 304-306.

120. Gérard C, Goldbeter A (2012) Entrainment of the mammalian cell cycle by the circadian clock: modeling two coupled cellular rhythms. PLoS Comput Biol 8: e1002516.

121. Gréchez-Cassiau A, Rayet B, Guillaumond F, Teboul M, Delaunay F (2008) The circadian clock component BMAL1 is a critical regulator of p21WAF1/ CIP1 expression and hepatocyte proliferation. J Biol Chem 283: 4535-4542.

122. Miyamoto N, Izumi H, Noguchi T, Nakajima Y, Ohmiya $Y$, et al. (2008) Tip60 is regulated by circadian transcription factor clock and is involved in cisplatin resistance. J Biol Chem 283: 18218-18226.

123. Janich P, Pascual G, Merlos-Suárez A, Batlle E, Ripperger J, et al. (2011) The circadian molecular clock creates epidermal stem cell heterogeneity. Nature 480: 209-214.

124. Bellet MM, Nakahata Y, Boudjelal M, Watts E, Mossakowska DE, et al. (2013) Pharmacological modulation of circadian rhythms by synthetic activators of the deacetylase SIRT1. Proc Natl Acad Sci U S A 110: 3333-3338.

125. Olmos Y, Brosens JJ, Lam EW (2011) Interplay between SIRT proteins and tumour suppressor transcription factors in chemotherapeutic resistance of cancer. Drug Resist Updat 14: 35-44.

126. Calvanese V, Lara E, Suárez-Alvarez B, Abu Dawud R, Vázquez-Chantada $M$ et al. (2010) Sirtuin 1 regulation of developmental genes during differentiation of stem cells. Proc Natl Acad Sci U S A 107: 13736-13741.

127. Thomas HE, Redgrave R, Cunnington MS, Avery P, Keavney BD, et al. (2008) 
Citation: Boudjelal M, Mosskowsaka DE, Farrow S (2013) Interlink between Nuclear Receptors, Posttranslational Modifications and the Biological Clock in Health and Diseases. J Carcinogene Mutagene S14: 005. doi:10.4172/2157-2518.S14-005

Circulating endothelial progenitor cells exhibit diurnal variation. Arterioscler Thromb Vasc Biol 28: e21-22.

128. Sletvold O, Laerum OD (1988) Alterations of cell cycle distribution in the bone marrow of aging mice measured by flow cytometry. Exp Gerontol 23: 43-58.

129. Fukuya H, Emoto N, Nonaka H, Yagita K, Okamura H, et al. (2007) Circadian expression of clock genes in human peripheral leukocytes. Biochem Biophys Res Commun 354: 924-928.

130. Abdelaal MA, Hashim IA, Zawawi TH, Felimban SK, Sobhi EM, et al. (2000) Circadian rhythm of granulocyte-macrophage colony-stimulating factor in normal subjects and neutropenic hospitalised patients. Ir J Med Sci 169: 5557.

131. Dinçol D, Akbulut $H$, Büyükçelik $A$, Içli $F$ (2000) Diurnal variations of serum GM-CSF levels. Cytokine 12: 1151-1155.

132. Sothern RB, Roitman-Johnson B, Kanabrocki EL, Yager JG, Roodell MM, et al. (1995) Circadian characteristics of circulating interleukin-6 in men. J Allergy Clin Immunol 95: 1029-1035.

133. Young MR, Matthews JP, Kanabrocki EL, Sothern RB, Roitman-Johnson B, et al. (1995) Circadian rhythmometry of serum interleukin-2, interleukin-10, tumor necrosis factor-alpha, and granulocyte-macrophage colony-stimulating factor in men. Chronobiol Int 12: 19-27.

134. Ptitsyn AA, Zvonic S, Conrad SA, Scott LK, Mynatt RL, et al. (2006) Circadian clocks are resounding in peripheral tissues. PLoS Comput Biol 2: e16.

135.Zvonic S, Ptitsyn AA, Conrad SA, Scott LK, Floyd ZE, et al. (2006) Characterization of peripheral circadian clocks in adipose tissues. Diabetes 55: 962-970.

136. Méndez-Ferrer S, Lucas D, Battista M, Frenette PS (2008) Haematopoietic stem cell release is regulated by circadian oscillations. Nature 452: 442-447.

137. Fu L, Pelicano H, Liu J, Huang P, Lee C (2002) The circadian gene Period2 plays an important role in tumor suppression and DNA damage response in vivo. Cell 111: 41-50.

138. Yang X, Wood PA, Oh EY, Du-Quiton J, Ansell CM, et al. (2009) Down regulation of circadian clock gene Period 2 accelerates breast cancer growth by altering its daily growth rhythm. Breast Cancer Res Treat 117: 423-431.

139. Kondratov RV, Kondratova AA, Gorbacheva VY, Vykhovanets OV, Antoch MP (2006) Early aging and age-related pathologies in mice deficient in BMAL1, the core componentof the circadian clock. Genes Dev 20: 1868-1873.

140. Antoch MP, Gorbacheva VY, Vykhovanets O, Toshkov IA, Kondratov RV et al. (2008) Disruption of the circadian clock due to the Clock mutation has discrete effects on aging and carcinogenesis. Cell Cycle 7: 1197-1204.

141. Innominato PF, Focan C, Gorlia T, Moreau T, Garufi C, et al. (2009) Circadian rhythm in rest and activity: a biological correlate of quality of life and a predictor of survival in patients with metastatic colorectal cancer. Cancer Res 69: 47004707

142. Lévi F, Okyar A, Dulong S, Innominato PF, Clairambault J (2010) Circadian timing in cancer treatments. Annu Rev Pharmacol Toxicol 50: 377-421.

143. Takane H, Ohdo S, Yamada T, Yukawa E, Higuchi S (2000) Chronopharmacology of antitumor effect induced by interferon-beta in tumorbearing mice. J Pharmacol Exp Ther 294: 746-752.

144. Lévi F, Okyar A (2011) Circadian clocks and drug delivery systems: impact and opportunities in chronotherapeutics. Expert Opin Drug Deliv 8: 1535-1541.

145.Longley DB, Harkin DP, Johnston PG (2003) 5-fluorouracil: mechanisms of action and clinical strategies. Nat Rev Cancer 3: 330-338.

146. Innominato PF, Lévi FA, Bjarnason GA (2010) Chronotherapy and the molecular clock: Clinical implications in oncology. Adv Drug Deliv Rev 62: 979-1001.

147. Savvidis C, Koutsilieris M (2012) Circadian rhythm disruption in cancer biology. Mol Med 18: 1249-1260.

148. Iurisci I, Filipski E, Reinhardt J, Bach S, Gianella-Borradori A, et al. (2006) Improved tumor control through circadian clock induction by Seliciclib, a cyclin-dependent kinase inhibitor. Cancer Res 66: 10720-10728.

149. Lévi F, Filipski E, lurisci I, Li XM, Innominato P (2007) Cross-talks between circadian timing system and cell division cycle determine cancer biology and therapeutics. Cold Spring Harb Symp Quant Biol 72: 465-475.
150.Levi F, Altinok A, Goldbeter A (2011) Circadian rhythms and cancerchronotherapeutics. Chapter 15. In: Cesario A, Marcus FB. editors. Cancer Systems Biology, Bioinformatics and Medicine: Research and Clinical Applications. Springer Dordrecht Heidelberg; London, New York.

151. Li MD, Li CM, Wang Z (2012) The role of circadian clocks in metabolic disease. Yale J Biol Med 85: 387-401.

152. Kelly MA, Rees SD, Hydrie MZ, Shera AS, Bellary S, et al. (2012) Circadian gene variants and susceptibility to type 2 diabetes: a pilot study. PLoS One 7: e32670.

153. Turek FW, Joshu C, Kohsaka A, Lin E, Ivanova G, et al. (2005) Obesity and metabolic syndrome in circadian Clock mutant mice. Science 308: 1043-1045.

154. Yin L, Wu N, Curtin JC, Qatanani M, Szwergold NR, et al. (2007) Reverbalpha, a heme sensor that coordinates metabolic and circadian pathways. Science 318: 1786-1789.

155. Barclay JL, Husse J, Bode B, Naujokat N, Meyer-Kovac J, et al. (2012) Circadian desynchrony promotes metabolic disruption in a mouse model of shiftwork. PLoS One 7: e37150.

156. Shimba S, Ogawa T, Hitosugi S, Ichihashi Y, Nakadaira Y, et al. (2011) Deficient of a clock gene, brain and muscle Arnt-like protein-1 (BMAL1) induces dyslipidemia and ectopic fat formation. PLoS One 6: e25231.

157. Stokkan KA, Yamazaki S, Tei H, Sakaki Y, Menaker M (2001) Entrainment of the circadian clock in the liver by feeding. Science 291: 490-493.

158. Scheer FA, Hilton MF, Mantzoros CS, Shea SA (2009) Adverse metabolic and cardiovascular consequences of circadian misalignment. Proc Natl Acad Sci U S A 106: 4453-4458.

159. Garaulet M, Madrid JA (2009) Chronobiology, genetics and metabolic syndrome. Curr Opin Lipidol 20: 127-134.

160. Bechtold DA, Gibbs JE, Loudon AS (2010) Circadian dysfunction in disease Trends Pharmacol Sci 31: 191-198.

161. Straub RH, Cutolo M (2007) Circadian rhythms in rheumatoid arthritis: implications for pathophysiology and therapeutic management. Arthritis Rheum 56: 399-408.

162. Ferraz E, Borges MC, Terra-Filho J, Martinez JA, Vianna EO (2006) Comparison of $4 \mathrm{AM}$ and $4 \mathrm{PM}$ bronchial responsiveness to hypertonic saline in asthma. Lung 184: 341-346.

163. Liu J, Malkani G, Shi X, Meyer M, Cunningham-Runddles S, et al. (2006) The circadian clock Period 2 gene regulates gamma interferon production of NK cells in host response to lipopolysaccharide-induced endotoxic shock. Infect Immun 74: 4750-4756.

164.Smolensky MH, Lemmer B, Reinberg AE (2007) Chronobiology and chronotherapy of allergic rhinitis and bronchial asthma. Adv Drug Deliv Rev 59: 852-882.

165. Terazono H, Mutoh T, Yamaguchi S, Kobayashi M, Akiyama M, et al. (2003) Adrenergic regulation of clock gene expression in mouse liver. Proc Natl Acad Sci U S A 100: 6795-6800.

166. Burioka N, Fukuoka Y, Koyanagi S, Miyata M, Takata M, et al. (2010) Asthma: Chronopharmacotherapy and the molecular clock. Adv Drug Deliv Rev 62 946-955.

167. Gibbs JE, Blaikley J, Beesley S, Matthews L, Simpson KD, et al. (2012) The nuclear receptor REV-ERBII mediates circadian regulation of innate immunity through selective regulation of inflammatory cytokines. Proc Natl Acad Sci U S A 109: 582-587

168. McCarthy MJ, Welsh DK (2012) Cellular circadian clocks in mood disorders. J Biol Rhythms 27: 339-352

169. Lewy AJ, Emens JS, Songer JB, Sims N, Laurie AL, et al. (2009) Winter Depression: Integrating mood, circadian rhythms, and the sleep/wake and light/dark cycles into a bio-psycho-social-environmental model. Sleep Med Clin 4: 285-299.

170. Souêtre E, Salvati E, Belugou JL, Pringuey D, Candito M, et al. (1989) Circadian rhythms in depression and recovery: evidence for blunted amplitude as the main chronobiological abnormality. Psychiatry Res 28: 263-278.

171.Soria V, Martínez-Amorós E, Escaramís G, Valero J, Pérez-Egea R, et al. (2010) Differential association of circadian genes with mood disorders: CRY1 
Citation: Boudjelal M, Mosskowsaka DE, Farrow S (2013) Interlink between Nuclear Receptors, Posttranslational Modifications and the Biological Clock in Health and Diseases. J Carcinogene Mutagene S14: 005. doi:10.4172/2157-2518.S14-005

Page 16 of 16

and NPAS2 are associated with unipolar major depression and CLOCK and VIP with bipolar disorder. Neuropsychopharmacology 35: 1279-1289.

172. Masana MI, Sumaya IC, Becker-Andre M, Dubocovich ML (2007) Behavioral characterization and modulation of circadian rhythms by light and melatonin in $\mathrm{C} 3 \mathrm{H} / \mathrm{HeN}$ mice homozygous for the RORbeta knockout. Am J Physiol Regul Integr Comp Physiol 292: R2357-2367.

173. Hampp G, Ripperger JA, Houben T, Schmutz I, Blex C, et al. (2008) Regulation of monoamine oxidase $\mathrm{A}$ by circadian-clock components implies clock influence on mood. Curr Biol 18: 678-683.
174. Lamont EW, Legault-Coutu D, Cermakian N, Boivin DB (2007) The role of circadian clock genes in mental disorders. Dialogues Clin Neurosci 9: 333 342.

175. Meng QJ, Logunova L, Maywood ES, Gallego M, Lebiecki J, et al. (2008) Setting clock speed in mammals: the CK1 epsilon tau mutation in mice accelerates circadian pacemakers by selectively destabilizing PERIOD proteins. Neuron 58: 78-88.

This article was originally published in a special issue, Cancer Diagnosis,

Treatment and Therapy handled by Editor(s). Dr. Said Dermime, King

Fahad Specialist Hospital Dammam, Saudi Arabia 